\title{
Metodologia para Avaliação do Potencial Deletério de Resíduos em Matrizes Cimentícias: Contribuição à Norma de Desempenho
}

\author{
Denise Carpena Coitinho Dal Molin \\ Angela Borges Masuero \\ Natália dos Santos Petry \\ Aguida Gomes de Abreu \\ Simone Dornelles Venquiruto
}

\section{Introdução}

Tudo que nos cerca um dia será resíduo: casas, automóveis, móveis, pontes, aviôes. A este total, são somados todos os resíduos do processo de extração de matérias-primas, de produção de bens e de produção agrícola. Assim, em qualquer sociedade, a quantidade de resíduos gerados supera a quantidade de bens consumidos. A sociedade industrial, ao multiplicar a produção de bens, agravou este processo (ROCHA; JOHN, 2003).

Atualmente dentro do desenvolvimento sustentável, onde busca-se suprir as necessidades da geração atual sem comprometer as próximas, cinco principios fundamentais são adotados: repensar, recusar, reduzir, reutilizar e reciclar. Sendo que três destes são essenciais para atenuar os danos ambientais gerados pelos resíduos: minimizar a sua geração, reutilizá-los ou reciclá-los. Dentre estas alternativas, muitas vezes não é possível a diminuição de geração, tornando-se essencial a reutilização e reciclagem dos resíduos.

Neste contexto, a cadeia produtiva da indústria da construçáo civil ocupa papel de destaque, possuindo enorme potencial para aumentar o volume de materiais que recicla, em função da grande quantidade de materiais consumidos. Esta reciclagem e/ou reutilizaçáo de resíduos pela construçáo civil pode auxiliar na minimização da extração da matéria prima da natureza e 
também auxiliar na escassez dos materiais que se depara, uma vez que a cadeia produtiva da construção civil consome entre 20 e 50\% dos recursos naturais de todo o planeta (JOHN, 2001).

Dessa forma, a necessidade de reciclar resíduos agrícolas e/ou industriais tem motivado cada vez mais pesquisas, visando minimizar o impacto ambiental provocado pelo acúmulo destes resíduos, através do desenvolvimento de aplicaçóes adequadas aos mesmos. Muitos resíduos podem ser utilizados da forma como são gerados, outros necessitam diferentes tratamentos para potencializar suas características.

É de consenso geral que o desenvolvimento sustentável requer construir usando menos materiais, e/ou substituir as matérias-primas naturais por resíduos, de forma a impactar menos sobre a natureza. Por outro lado, não se pode abdicar da qualidade do novo produto gerado e, principalmente, de sua durabilidade.

No ano de 2013, entrou em vigor no Brasil a Norma de Desempenho (NBR 15.575:2013). Esta norma foca nos requisitos dos usuários para o edifício habitacional e seus sistemas, quanto ao seu comportamento em uso e não na prescrição de como os sistemas devem ser construídos. Entretanto, quanto às questóes de sustentabilidade, a norma apresenta alguns itens, porém não contempla a utilização de resíduos na construção civil.

Ao longo de mais de 20 anos, o Núcleo Orientado para a Inovação da Edificação - NORIE, vinculado à UFRGS, vem desenvolvendo pesquisas que contemplam a utilização de resíduos das mais diferentes maneiras dentro das matrizes à base de cimento, tais como Silveira (1996), Curutchet (1998), Ferreira (1999), Gonçalves (2000), Cassal (2000), Sensale (2000), Moura (2000), Masuero (2001), Mancio (2001), Leite (2001), Geyer (2001), Geyer (2001), Gumieri (2001), Vieira (2003), Souza (2003), Brehm (2004), Abreu (2004), Polisseni (2005), Vargas (2006), Pouey (2006), Silveira (2007), Recena (2011), Cordeiro (2013), Giordani (2014), Petry (2015), entre outros.

John (2000), em sua tese de livre docência, propóe uma metodologia de pesquisa e desenvolvimento, com uma abordagem teórica, conduzindo o processo de pesquisa visando a transformação de um resíduo em material de construção. John (2000) propóe várias etapas, que iniciam com a identificação e quantificação dos resíduos, seleção do resíduo a ser investigado, 
caracterizaçáo, aplicação, desenvolvimento do produto, avaliaçáo do produto, análise de desempenho ambiental e transferência da tecnologia.

Ao se investir na pesquisa de um resíduo com potencial de utilizaçáo em matrizes de base cimentícia, diferentes aspectos devem ser contemplados, como apresentam John e Zordan (2001). Os autores relacionam, na metodologia por eles proposta, a necessidade de serem atendidos na investigação os seguintes tópicos: a geração dos resíduos, a sua caracterização, a seleção das possíveis aplicaçóes, o desenvolvimento do produto, a avaliação do produto e a transferência de tecnologia. Ainda, no desdobramento dos tópicos da metodologia proposta por John e Zordan (2001), também devem consideradas questôes tais como o volume de resíduos gerado, a variabilidades destes, aspectos ambientais, a análise do ciclo de vida, entre outros. Neste contexto, destaca-se como de fundamental importância o conhecimento do resíduo, obtido através de sua caracterização química e física.

Os dois trabalhos apresentados, tanto o de John (2000), quanto o de John e Zordan (2001), visam uma metodologia com abordagem teórica para o emprego do resíduo. Já o presente trabalho visa propor uma metodologia prática para o emprego de resíduos em produtos de base cimentícia.

Consequentemente, para que seja possível a inserção de um determinado resíduo em uma matriz de cimento Portland, há a necessidade de que se realize uma investigação exaustiva no sentido de se conhecer as características do resíduo, em nível macro e microestrutural. Isto porque, além desse conhecimento possibilitar o direcionamento do resíduo à aplicação mais viável, também permite antever possíveis efeitos deletérios que possam resultar da combinação do resíduo com o cimento Portland. Neste sentido, a metodologia prática proposta neste trabalho para o estudo de resíduos dos quais se tem pouca ou nenhuma informaçáo, visa orientar o usuário, de forma sistematizada, a focar a investigaçáo a partir da composiçáo química e mineralógica do resíduo quanto do cimento Portland. Ao seguir o fluxograma, busca-se identificar na combinação resíduo-cimento a possibilidade de ocorrerem comportamentos adversos, propondo-se alternativas para a avaliação.

Assim, o objetivo principal deste trabalho é a apresentação de uma metodologia prática de avaliação, para testar a viabilidade de utilização de resíduos com potencial de uso em matrizes cimentícias do ponto de vista ambiental e da durabilidade dos elementos construtivos. 


\section{Levantamento do Conhecimento e Sistematização}

O trabalho compreende duas etapas distintas: a primeira, um estudo exploratório, visando a identificaçáo de resíduos já pesquisados, a seleção destes, a identificação da composição química, o comportamento em matrizes cimentícias e o levantamento de ensaios utilizados para avaliar os processos de degradação em matrizes cimentícias. A segunda etapa consiste na elaboração de fluxogramas, orientando os ensaios a serem realizados em função da presença ou náo de determinado composto ou elemento, que pode vir a causar problemas, principalmente de durabilidade, nas matrizes cimentícias. A representação esquemática do passo-a-passo da pesquisa é apresentada na Figura 1.

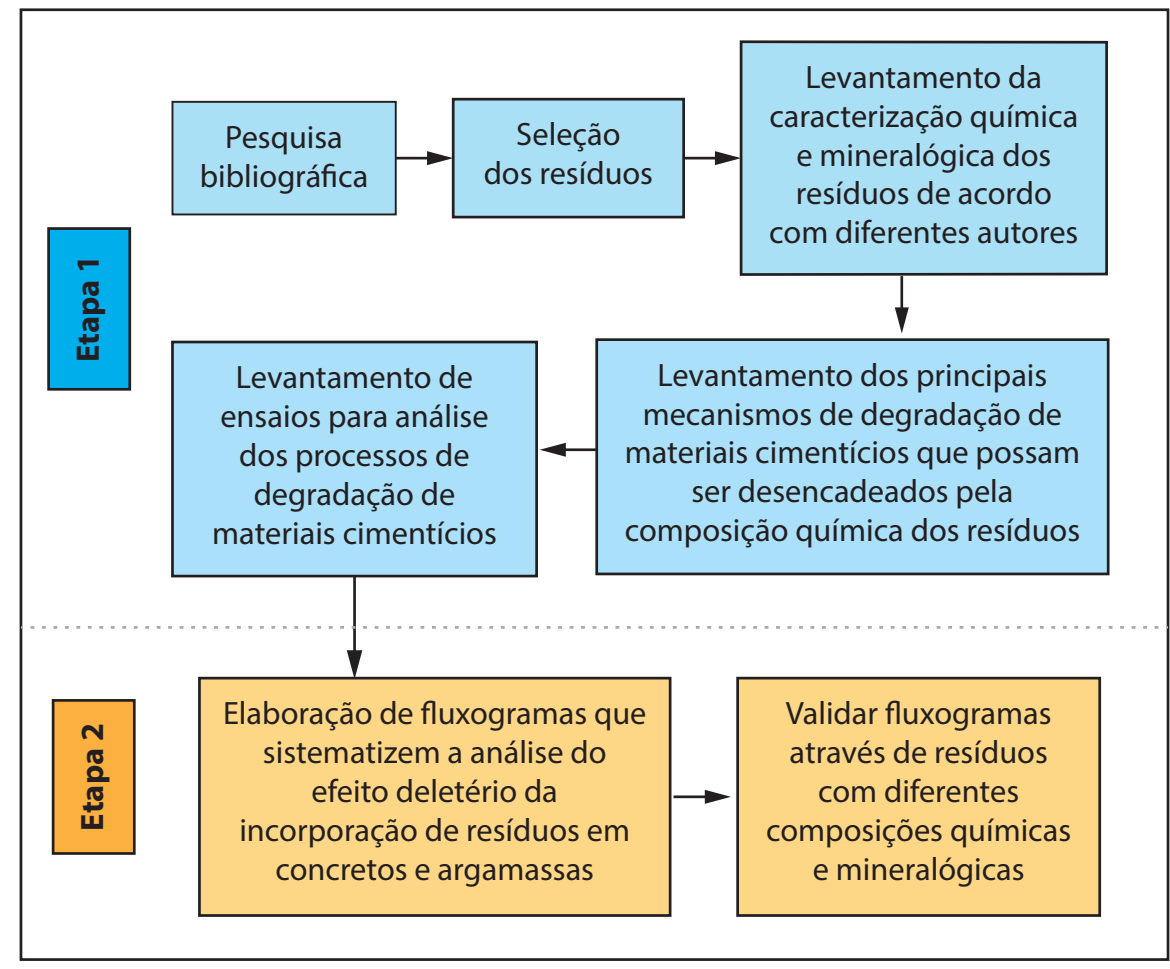

Figura 1. Diagrama das etapas da pesquisa. 


\subsection{Etapa 1 - Estudo Exploratório}

Através de pesquisa bibliográfica foi levantado o maior número possível de estudos que envolveram a utilização de resíduos, tanto em concretos como em argamassas. Nesse estudo inicial foram identificados pelo menos 37 resíduos (Tabela 1), que foram pesquisados e encontraram-se em diferentes níveis de aprofundamento.

Tabela 1. Relação de resíduos com possibilidades de utilização em matrizes cimentícias, conforme bibliografia (GEYER, 2001; MASUERO et al., 2001; VARGAS, 2002; GONÇALVES et al., 2002; SOUZA, 2003; DELLA et al.; 2006, entre outros).

\begin{tabular}{|c|c|c|}
\hline Resíduo & Resíduo & Resíduo \\
\hline $\begin{array}{l}\text { 1. Areia de fundição - não } \\
\text { fenólicas }\end{array}$ & $\begin{array}{l}\text { 15. Fibra de garrafa PET - } \\
\text { polietileno terefitalado }\end{array}$ & $\begin{array}{l}\text { 26. Resíduo de tijolo } \\
\text { refratário dolomítico }\end{array}$ \\
\hline 2. Borracha de pneu & 16. Fibra de bambu & 27. Resíduo de gesso \\
\hline 3. Cinza do bagaço de cana & 17. Fluffy (siderurgia) & 28. Resíduo da produção de \\
\hline de açúcar & 18. GRITS (resíduos da ind. & biodiesel \\
\hline 4. Cinza de carbureto & de celulose) & 29. Resíduo da estação de \\
\hline 5. Cinza de casca de arroz & 19. Lama vermelha & tratamento de água \\
\hline 6. Dregs (resíduos da ind. de & 20. Lodo de anodização & 30. Resíduo de contrafortes \\
\hline celulose) & 21. Lodo ETE - resíduo da & 31. Resíduo de \\
\hline 7. Escória de aciaria elétrica & estação de tratamento de & beneficiamento de rocha de \\
\hline 8. Escória de alto forno & esgoto & ágata \\
\hline 9. Escória de aciaria LD & 22. Lodo ETA - resíduos da & 32. Resíduo de construção e \\
\hline 10. Escória inoxidável & estação de tratamento de & demolição (RCD) \\
\hline 11. Escória de fundição & água & 33. Serragem cromada \\
\hline 12. Escória de cobre & 23. Metacaulim & 34. Serragem de madeira \\
\hline 13. Escória de ferro-cromo & 24. Pó de aciaria & 35. Sílica ativa \\
\hline \multirow[t]{2}{*}{ 14. Fibra de côco } & 25. Pó de corte de mármore & 36. Vidro reciclado \\
\hline & e granito & $\begin{array}{l}\text { 37. Sinter feed (resíduo de } \\
\text { minério de ferro) }\end{array}$ \\
\hline
\end{tabular}

Tendo como referência as pesquisas realizadas (LEITE, 2001; MANCIO, 2001; ZARDO et al., 2004; RODRIGUES, 2008; entre outros), e as características químicas e físicas dos diferentes resíduos, estes foram agrupados conforme sua possibilidade de emprego nas matrizes cimentícias. A Tabela 2 apresenta a classificação proposta. 
Tabela 2. Classificação dos resíduos conforme sua possibilidade de utilização em matrizes cimentícias.

\begin{tabular}{|c|c|c|}
\hline $\begin{array}{l}\text { Possibilidade } \\
\text { de utilização }\end{array}$ & Resíduo & \\
\hline Adição & - Sílica ativa; & - Cinza de casca de arroz; \\
\hline mineral & - Cinza volante; & - Pó de aciaria; \\
\hline Pozolanas e/ & - Metacaulim; & - Escória de alto forno; \\
\hline \multirow[t]{7}{*}{ ou fíler* } & - Cinza de cana-de-açúcar; & - Escória de aciaria; \\
\hline & - Pó de corte de mármore e granito; & - Escória de cobre; \\
\hline & - Cinza de pó de madeira; & - Escória inoxidável; \\
\hline & - Cinza de lodo ETE - resíduo da & - Escória ferro-cromo; \\
\hline & estação de tratamento de esgoto; & - Escória de fundição; \\
\hline & - Cinza de lodo ETA - resíduos da & - Pó de rolagem de ágata; \\
\hline & estação de tratamento de água; & - Pó de pneu; \\
\hline \multirow[t]{7}{*}{ Agregados } & - Escória de alto forno; & - Resíduo de mármore; \\
\hline & - Escória de aciaria; & - Resíduo de granito; \\
\hline & - Escória de cobre; & - Resíduo da construção e \\
\hline & - Escória inoxidável; & demolição; \\
\hline & - Escória ferro-cromo; & - Vidro reciclável \\
\hline & - Escória de fundição; & - Contraforte; \\
\hline & - Resíduo de ágata; & - Pneu. \\
\hline \multirow[t]{4}{*}{ Fibras } & - Contraforte; & - Fibra de cana-de-açúcar; \\
\hline & - Fibra de bambu; & - Fibra de sisal; \\
\hline & - Fibra de pet; & - Pneu. \\
\hline & - Fibra de côco; & \\
\hline
\end{tabular}

* Dependendo do tipo de calcinação e resfriamento adotado, o material poderá apresentar características pozolânicas ou de fíler.

Entende-se que as investigaçóes devam ser conduzidas no sentido de identificar, nos resíduos, elementos ou compostos (p. ex. $\mathrm{CaO}_{\text {livre, }} \mathrm{MgO}$ (periclásio), $\mathrm{SiO}_{2}, \mathrm{~K}, \mathrm{Na}, \mathrm{Cl}, \mathrm{Zn}$ ) que, mesmo em menores proporçóes ou 
traços, possam vir a impactar de forma negativa nas reaçóes de hifratação do cimento, podendo alterar sua pega e endurecimento, comprometer a resistência em idades mais avançadas e a durabilidade do produto obtido. Pode ocorrer também de compostos ou elementos presentes no resíduo, mesmo que em teores bastante reduzidos, somados aos constituintes do cimento, totalizarem valores além de um máximo admissível no aglomerante, argamassa ou concreto.

Destaca-se ainda, que na investigação devem ser contemplados ao máximo os aspectos inerentes a cada resíduo, tais como a variabilidade do processo que leva à geração deste, possíveis regionalidades, entre outros.

Para a caracterização do resíduo, análises por fluorescência de raios-X (FRX) e por difração por raios-X (DRX), para identificar os elementos presentes e a mineralogia da fração cristalizada, respectivamente, são os ensaios inicialmente mais utilizados. Porém, análises químicas específicas e análises mais complexas podem vir a ser importantes para o conhecimento do resíduo e de fenômenos envolvidos no processo de pega e endurecimento da mistura deste com o cimento. Citam-se, entre outras, a espectrofotometria por absorção atômica, análise térmica (TG/DTA), análise petrográfica, microscopia eletrônica de varredura, no modo elétrons secundários ou retroespalhados, que podem ser usados em conjunto em EDS ou WDs, análise granulométrica a laser, superfície específica por adsorção de nitrogênio (BET) e porosimetria por intrusão de mercúrio. As técnicas de análise são utilizadas sempre em associação, de forma complementar.

Após a identificação dos resíduos, foram organizadas planilhas nas quais reuniram-se os resultados de caracterização química encontrados por diferentes autores. A tabela 3 apresenta características químicas de alguns dos resíduos pesquisados. Esses valores, expressos na tabela 3, representam faixas aproximadas, que podem ser encontradas nestes resíduos, uma vez que existe uma variabilidade em função da origem e do tempo. 


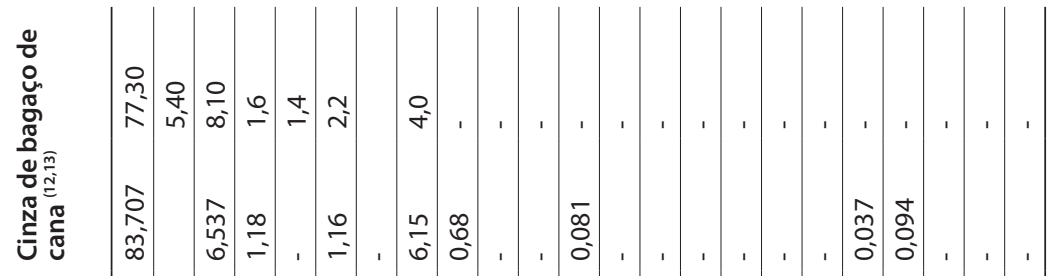

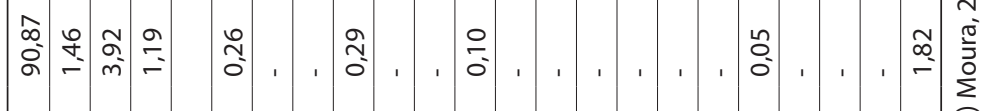

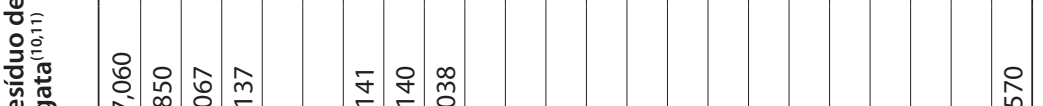

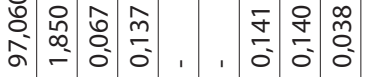

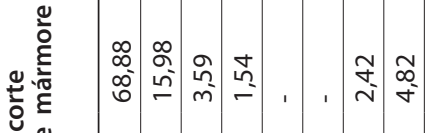

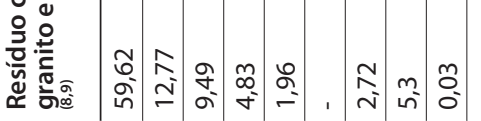

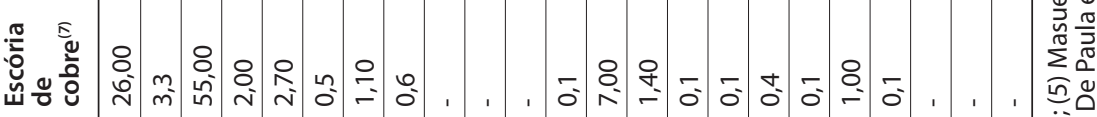

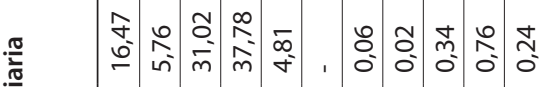

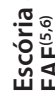

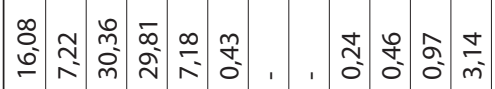

$\frac{\dot{2}}{\frac{\pi}{2}}$

产突

$\frac{1}{0}$

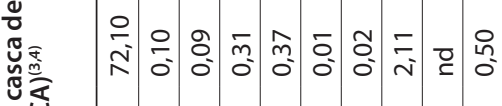

惢

ก ฮ่ ปे

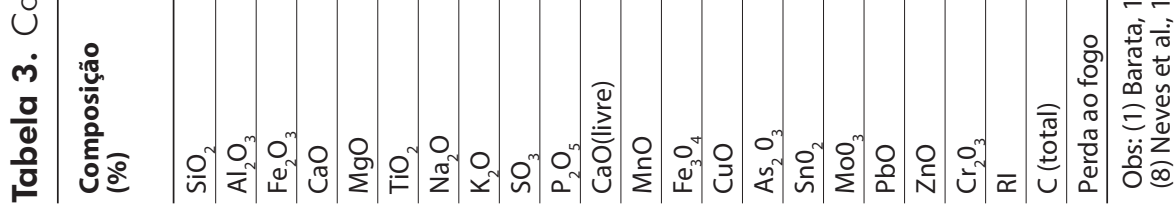


A tabela 4 apresenta as fases presentes identificadas, em geral, em análise por difração de raios-X

Tabela 4. Compostos identificados (fases) em resíduos pesquisados, exemplos.

\begin{tabular}{|c|c|c|c|}
\hline $\begin{array}{l}\text { Escória de } \\
\text { aciaria elétrica } \\
(\mathrm{EAE})^{1}\end{array}$ & $\begin{array}{l}\text { Resíduo de corte de } \\
\text { granito (RCG) }\end{array}$ & $\begin{array}{l}\text { Escória de aciaria } \\
\text { LD (EALD) resfriada } \\
\text { lentamente }^{3}\end{array}$ & $\begin{array}{l}\text { Escória de aciaria } \\
\text { LD (EALD) resfriada } \\
\text { bruscamente - } \\
\text { usina }^{3}\end{array}$ \\
\hline $\begin{array}{l}\text { Periclase - } \\
\mathrm{MgO}\end{array}$ & $\begin{array}{l}\text { Anordita - } \\
\mathrm{CaAl}_{2} \mathrm{SiO}_{2} \mathrm{O}_{8}\end{array}$ & $\begin{array}{l}\text { larnita - } \\
{\mathrm{\beta} 2 \mathrm{CaO} \cdot \mathrm{SiO}_{2}}\end{array}$ & $\begin{array}{l}\text { bredigita - } \\
\mathrm{a}^{\prime} \mathrm{C} 2 \mathrm{~S}\end{array}$ \\
\hline $\begin{array}{l}\text { Wustita - } \\
\text { FeO }\end{array}$ & $\begin{array}{l}\text { Microclino - } \\
\mathrm{KAISi}_{3} \mathrm{O}_{8}\end{array}$ & $\begin{array}{l}\text { óxido de cálcio livre - } \\
\mathrm{CaO}\end{array}$ & $\begin{array}{l}\text { silicato tricálcico - } \\
\mathrm{C}_{3} \mathrm{~S}\end{array}$ \\
\hline $\begin{array}{l}\text { Wollastonita - } \\
\mathrm{CaSiO}_{3} \\
\text { Óxido de } \\
\text { Cálcio - } \\
\mathrm{CaO} \\
\text { Larnita - } \\
\mathrm{Ca}_{2} \mathrm{SiO}_{4} \\
\mathrm{Clinocloro} \mathrm{-} \\
(\mathrm{Mg}, \mathrm{Al}, \mathrm{Fe})_{4} \\
\mathrm{O}_{10}(\mathrm{OH})_{8}\end{array}$ & $\begin{array}{l}\text { Muscovita - } \\
\mathrm{KAl}_{2} \mathrm{Si}_{3} \mathrm{AlO}_{10}(\mathrm{OH})_{2} \\
\text { Quartzo - } \\
\mathrm{SiO}_{2} \\
\text { Tremolite - } \\
\left(\mathrm{Ca}_{2} \mathrm{Mg}_{5} \mathrm{Si}_{8} \mathrm{O}_{22}(\mathrm{OH})_{2}\right)\end{array}$ & $\begin{array}{l}\text { hidróxido de cálcio - } \\
\mathrm{Ca}(\mathrm{OH}) 2 \\
\text { calcita - } \\
\mathrm{CaCO}_{3} \\
\text { ferrita dicálcica - } \\
2 \mathrm{CaO} \text {. Fe }{ }_{2} \mathrm{O}_{3} \\
\text { wustita - } \\
\text { FeO } \\
\text { hematita - } \\
\text { Fe2O3 } \\
\text { óxido de cálcio, } \\
\text { alumínio e ferro - } \\
\mathrm{CaAl}_{8} \mathrm{Fe}{ }_{4} \mathrm{O}_{14} \\
\text { hausmannita - } \\
\text { (Mn,Mg)(Mn,Fe)2O4; } \\
\text { periclásio - } \\
\mathrm{MgO} \\
\text { ferro metálico - } \\
\text { Fe }{ }^{0}\end{array}$ & 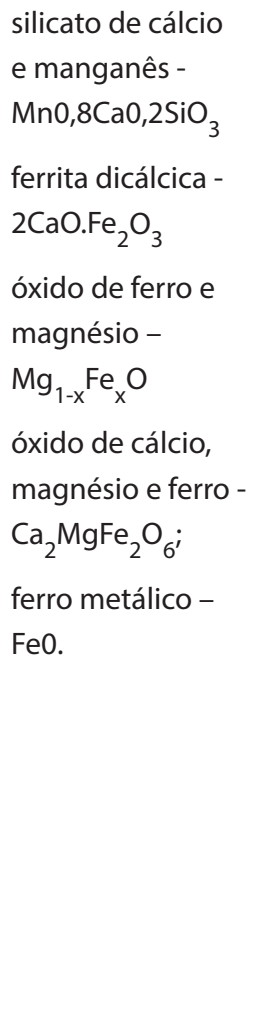 \\
\hline
\end{tabular}

(1) Masuero et al., 2004; (2) Gonçalves et al., 2002; (3) Gumieri, 2002. 
Pela importância que tem a composição química do resíduo para compor misturas com cimentos, as consequências ou efeitos da presença de determinados compostos ou traços nas misturas são apresentadas na sequência.

$\mathrm{Na}$ Tabela 3, verifica-se que pode ocorrer uma grande diferença da composição química dos resíduos, como por exemplo, a cinza de casca de arroz. Esta variabilidade pode ser atribuída à forma de obtenção da cinza, mais especificamente tempo e temperatura de queima. No resíduo de corte de granito, observa-se o teor de $\mathrm{K}$ elevado em relação aos demais resíduos apresentados na Tabela 3. No resíduo de ágata, o teor de Si; e assim por diante. Entretanto, a presença de determinado elemento náo significa dizer que o resíduo é inadequado para uso em matrizes com cimento. É necessário que se identifiquem a(s) fase(s) na(s) qual(is) determinado elemento químico é encontrado no resíduo. Pode ocorrer de o elemento químico ser constituinte de fases estáveis para as condiçóes de aplicação pretendida para o resíduo e, nesta condição, não seria prejudicial à matriz cimentícia. Assim, na Tabela 4 sáo apresentados exemplos de caracterização mineralógica.

Com as informaçóes reunidas e tendo em conta aspectos como os relacionados anteriormente, realizou-se a segunda etapa da pesquisa, que corresponde à elaboração de uma metodologia de avaliação.

Pretende-se ampliar a aplicação desta medodologia, que será apresentada a seguir, para o maior número possível de resíduos, deste modo desejase realizar uma catalogação destes materiais e disponibilizá-la, afim de difundir as pesquisas realizadas. Esta disponibilização será a partir de fichas catalográficas que conterão a aplicação da metodologia e informaçóes que se façam pertinentes. A figura 2 demostra como pretende-se catalogar essas informaçôes. 
Metodologia para Avaliação do Potencial Deletério de Resíduos... Cap. 4

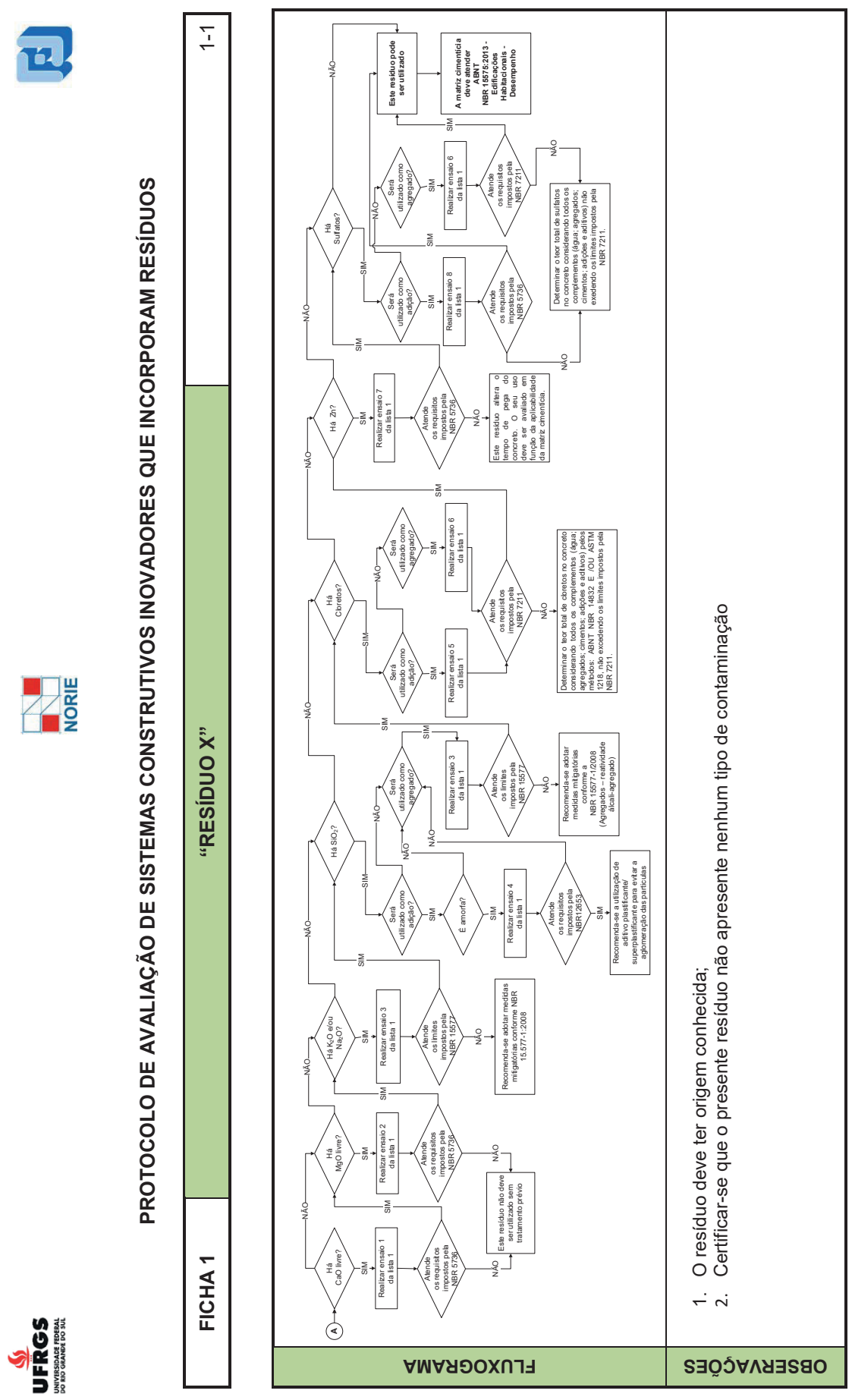

Figura 2. Modelo de Ficha catalográfica de resíduos. 


\subsubsection{Efeitos Deletérios Causados pelos Compostos}

Devido à grande diversidade de resíduos disponíveis com potencial de uso em concretos e argamassas, foi realizada uma seleção, optando-se por usar como referência para a estruturaçáo da metodologia os que apresentassem uma caracterização mais completa na bibliografia. Isso possibilitou a identificação dos compostos usualmente mais frequentes nos resíduos, cuja presença na matriz cimentícia pode ser deletéria.

Como comentado anteriormente, no levantamento bibliográfico, foi constatado que existe uma grande variedade de trabalhos disponíveis a respeito do reaproveitamento de resíduos na construção civil no Brasil e fora do pais. Entretanto, em muitos destes, o foco está voltado para a obtenção de produtos e seus desempenhos mecânicos destes. Nestes casos, a caracterização do resíduo utilizado normalmente, ou é mínima ou não informada.

A presença de determinados compostos ou elementos nos resíduos pode ser extremamente prejudicial às matrizes cimentícias, pois estes podem reagir com os compostos químicos do aglomerante, com seus produtos de hidratação e/ou com os agregados presentes. Assim, são descritos brevemente alguns dos principais compostos e seu efeito na matriz cimentícia.

\subsubsection{1. Óxido de Cálcio Livre (CaO livre) e Periclásio (MgO)}

Ao se hidratar, o óxido de cálcio livre forma a portlandita $\left(\mathrm{Ca}(\mathrm{OH})_{2}\right)$, cuja reação é acompanhada de aumento de volume na ordem de 97,6\% (CENTURIONE, 1993). No clínquer, o óxido cálcio livre $\left(\mathrm{CaO}_{\text {livre }}\right)$ é resultado de deficiências no processo de obtenção deste, podendo estar associado a problemas de moagem ou homogeneização da matéria prima, ou ainda, da dosagem excessiva do óxido de cálcio na farinha. Assim, o óxido de cálcio livre é um parâmetro de controle no processo de fabricação do clínquer, que se apresenta, em média, no teor de 1\%. Entretanto, o óxido de cálcio livre pode ser encontrado também em resíduos como, por exemplo, nas escórias siderúrgicas.

O óxido de magnésio (periclásio) aparece no clínquer como fase mineralógica, e tem como fonte os calcários magnesianos utilizados como matéria prima. Segundo Centurione (1993), na formação do clínquer, o óxido de magnésio presente na farinha tem participação na formação de diferentes fases do clínquer, principalmente na alita, substituindo o $\mathrm{CaO}$. Caso o teor de $\mathrm{MgO}$ seja superior a $2 \%$, aproximadamente, o material excedente se cristalizará sob a forma de periclásio (CENTURIONE, 1993). O óxido de magnésio reage mais lentamente, sendo responsável pela expansão em longo 
prazo (SERSALE, 1986'; SHOUSUN, $1980^{2}$ citados por MASUERO et al., 2004). De forma similar ao óxido de cálcio livre, o óxido de magnésio pode estar presente também nas escórias siderúrgicas.

A figura 3 ilustra detalhe do fluxograma, onde destaca-se a análise decorrente da presença de $\mathrm{CaO}_{\text {livre }}$.

A norma brasileira de referência para especificação de cimento Portland comum estabelece o limite máximo 6,5\% para o $\mathrm{MgO}$, sendo que os ensaios utilizados para realizar esta determinaçáo são estabelecidos pelas NBR NM 14:2012.

A identificação da presença de $\mathrm{CaO}_{\text {livre }}$ e $\mathrm{MgO}$ pode ser feita, entre outros, através de ensaios químicos, análise térmica e análise de difração de raios-X.

Para estudo da expansão pode ser utilizado o método proposto pela norma NBR 11582:2012 - Determinação da Expansibilidade Le Chatelier, que quando realizada a frio, relaciona a expansão à presença de $\mathrm{CaO}_{\text {livre }}$, enquanto no processo a quente visa à identificaçáo da presença do $\mathrm{MgO}$. Entretanto, ao se realizar apenas o ensaio a quente, o aumento de volume também pode ser atribuído à presença de $\mathrm{CaO}$ livre. Outros métodos de avaliação da expansibilidade podem ser encontrados em Gumieri (2002), Moura (2000) e Masuero (2001).

Gumieri (2002), ao estudar escórias de aciaria LD, destaca a importância de se avaliar, além das características químicas, também a granulometria e dimensão máxima característica do material, sua superfície específica e idade. A autora considera ainda que cada método de ensaio seria mais adequado para avaliar um parâmetro específico, ao invés do conjunto de parâmetros causadores da expansão.

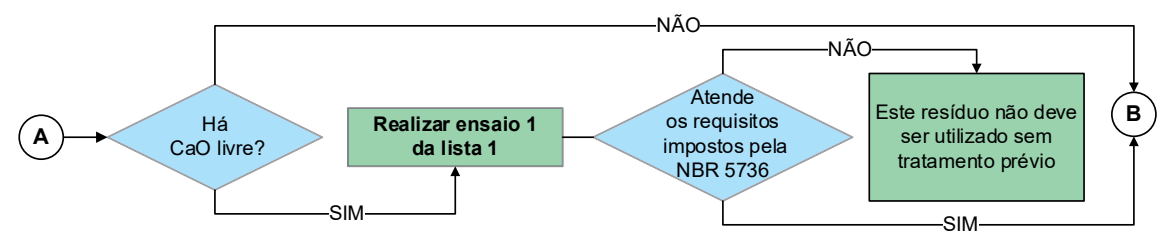

Figura 3. Detalhe do fluxograma, destacando-se a análise decorrente da presença de $\mathrm{CaO}_{\text {livre }}$.

1 SERSALE, R. et al. Chracterization and potencial uses of steel slag. Silicates Industriels, Bruxelles,v.51, p.163-170, 1986.

2 SHOUSUN, L. Effect of $\mathrm{MgO}$ in steel slag on soundness of cement. In: International Symposium On The Chemistry Of Cement, 7., 1980. Proceedings... Paris, 1980. p. 25-30. 
A figura 4 ilustra detalhe do fluxograma, onde destaca-se a análise decorrente da presença de $\mathrm{MgO}_{\text {livre }}$.

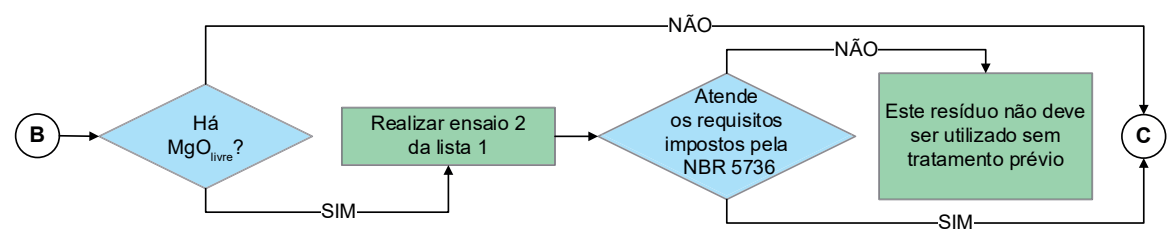

Figura 4. Detalhe do fluxograma, destacando-se a análise decorrente da presença de $\mathrm{MgO}_{\text {Livre }}$.

\subsubsection{2. Álcalis $\left(\mathrm{Na}_{2} \mathrm{O}\right.$ e $\left.\mathrm{K}_{2} \mathrm{O}\right)$}

No clínquer, os álcalis têm origem nos materiais argilosos contendo, entre outros, partículas finas de feldspatos, mica e ilita. Na fabricação do cimento, podem ocorrer também nas cinzas de carvão utilizado como combustível. Além de maior potencialidade de ocorrerem reações expansivas tipo álcaliagregado, são atribuídos à presença de compostos alcalinos variaçóes dos tempos de pega dos cimentos, empelotamento dos mesmos, formação de manchas no concreto, modificações no endurecimento (BLODA, 1967³, citado por CENTURIONE, 1993). O teor de álcalis nas pozolanas, como por exemplo, na cinza de casca de arroz, pode ser elevado e varia conforme a procedência da mesma (ABREU, 1998; KULAKOWSKI, 2002; SILVEIRA, 2007; RODRIGUES, 2008), assim como no caso da cinza de bagaço de cana (FRIAS et al., 2011). Porém, se o mineral contendo álcalis não é solúvel em ambientes de elevado $\mathrm{pH}$, este não deve causar problemas em misturas contendo cimento Portland (MEHTA e MONTEIRO, 2014).

Para a identificação da presença dos elementos $\mathrm{Na}$ e $\mathrm{K}$ em resíduos podem ser utilizados ensaios como a fluorescência de raios-X. A determinaçáo do teor de álcalis pode ser feita também por fotometria de chama utilizando a norma NBR 17:2012, prescrita para o cimento.

A figura 5 ilustra detalhe do fluxograma, onde destaca-se a análise decorrente da presença de $\mathrm{K}_{2} \mathrm{O}$ e/ou $\mathrm{Na}_{2} \mathrm{O}$.

3 BLODA, A.V. El problema de los álcalis em la concción del cemento Portland. Cemento Hormigón, Barcelona, v. 35, n. 5, set. 1967. p. 433-452. 


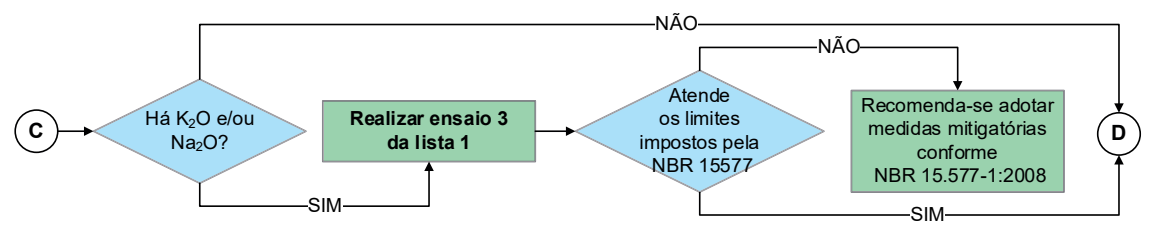

Figura 5. Detalhe do fluxograma, destacando-se a análise decorrente da presença de $\mathrm{K}_{2} \mathrm{O}$ e/ou $\mathrm{Na}_{2} \mathrm{O}$.

\subsubsection{Dióxido de Silício $\left(\mathrm{SiO}_{2}\right)$}

O dióxido de silício apresenta-se de várias formas, que são: quartzo, quartzito, tridimita, critobalita e opala. Dependendo da forma como encontra-se no agregado, este pode reagir com os álcalis do cimento, formando um gel que, na presença de água, expande, afetando a integridade das estruturas de concreto. Esta reação é denominada, na literatura, de reação álcali-sílica e/ou álcali-silicato.

As rochas ou resíduos que desencadeiam a reação álcali-sílica apresentam formas bem definidas como a sílica metaestável (tridimita e critobalita), sílica microcristalina amorfa (opala) e a sílica sob a forma de quartzo criptocristalino, considerada a forma mais desordenada e reativa (chert, flint e calcedônia) (PAULON, 1981).

A reação álcali-silicato é propiciada por minerais reativos que apresentam o retículo cristalino deformado, dessa forma o quartzo é considerado um destes minerais, devido às tensões de origem geológica (TIECHER, 2006).

Assim, é necessário que se realizem ensaios de análise petrográfica, para identificar a forma como o dióxido de silício está presente no agregado que se pretende utilizar nas matrizes cimentícias.

Para analisar o potencial reativo dos agregados existem vários ensaios reconhecidos internacionalmente, sendo: análise petrográfica ASTM C29508; NBR 15577-3:2008; NBR 7389:2009, método das barras, ASTM C22710, método acelerado das barras, ASTM C1260-14; NBR 15577-4:2008, determinação da expansão em prismas de concreto NBR 15577-4:2008; ASTM C1293-08, entre outros.

A figura 6 ilustra detalhe do fluxograma, onde destaca-se a análise decorrente da presença de $\mathrm{SiO}_{2}$. 


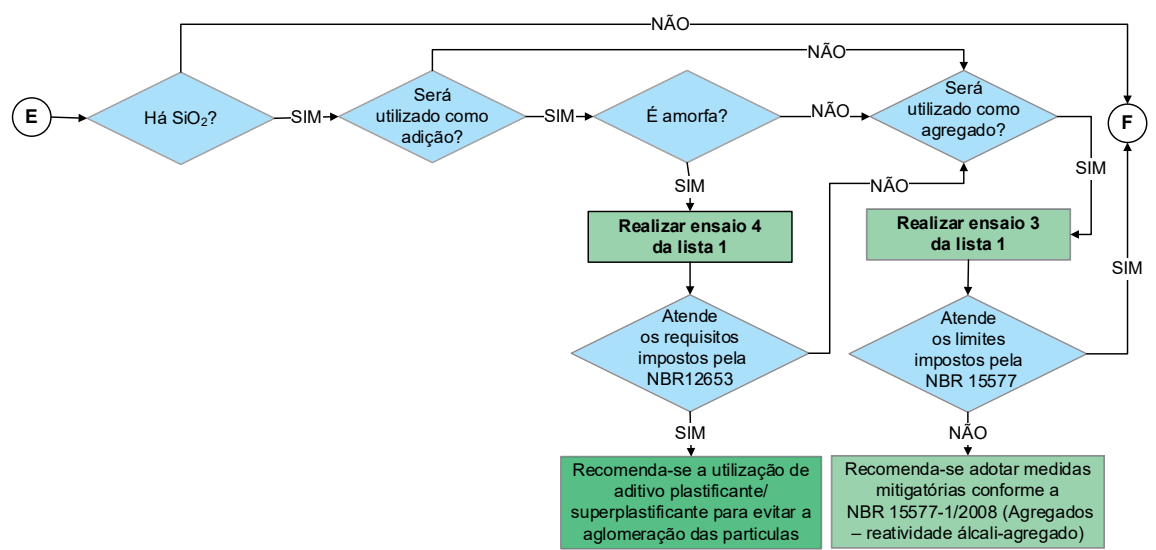

Figura 6. Detalhe do fluxograma, destacando-se a análise decorrente da presença de $\mathrm{SiO}_{2}$.

\subsubsection{4. Íon Cloreto $-\mathrm{Cl}^{-}$}

O efeito da presença do íon cloreto está associado diretamente à corrosão da armadura, em estruturas de concreto armado ou argamassa armada. Assim, o teor máximo admitido é rigorosamente limitado por norma, conforme a aplicação do concreto, estando os valores limites relacionados, em geral, à massa de cimento por metro cúbico de concreto.

Os valores limites para o teor cloretos podem ser encontrados nas normas NBR 7211:2009 e NBR 6118:2014. No resíduo, o teor de cloretos pode ser determinado através de ensaios como os estabelecidos na ASTM C1206-10.

A figura 7 ilustra detalhe do fluxograma, onde destaca-se a análise decorrente da presença de cloretos. 


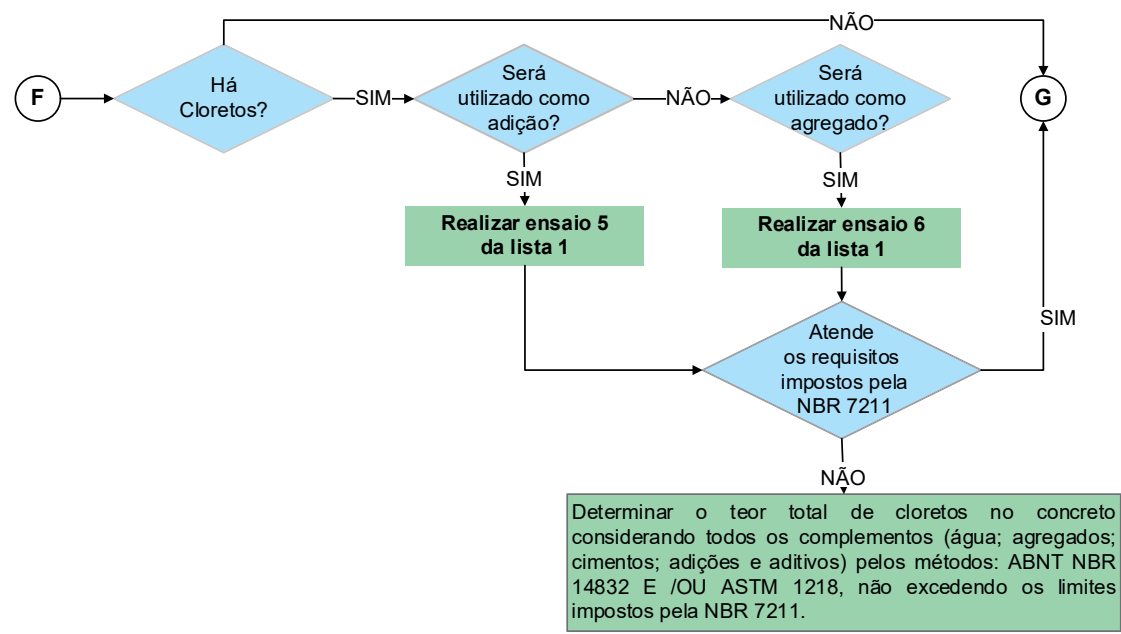

Figura 7. Detalhe do fluxograma, destacando-se a análise decorrente da presença de Cloretos.

\subsubsection{5. Óxido de Zinco ( $\mathrm{ZnO})$}

$\mathrm{O}$ óxido de zinco $(\mathrm{ZnO})$ pode ser encontrado em resíduos, como por exemplo no pó de aciaria elétrica (VARGAS, 2002).

Odler e Schmidt (1980) $)^{4}$, citados por Maringolo (2001), afirmam que óxido de zinco em teores de até $0,5 \%$ no clínquer pode ser acomodado no processo de fabricação. Porém, teores superiores a $1 \%$ podem comprometer a hidratação, retardando-a, além de reduzir as resistências iniciais [ODLER e ABDUL-MAULA, (1980a $\left.\mathrm{a}^{5} \mathrm{~b}^{6}\right)$; KNÖFEL, (1978) ${ }^{7}$, citados por MARINGOLO (2001)]. A reação de retardamento da hidratação foi

4 ODLER, I; SCHMIDT, O. Structure and properties of Portland cement clinker doped with zinc oxide. Journal of American Ceramic Society, Ohio, USA, p. 13-16, 1980.

5 ODLER, I.; ADBUL-MAULA,S. Effect of mineralizers on the burning process of Portland cement clinker, Part 1: Kinectics of the process. Zement-Kalk-Gips, Wiesbaden, n. 3, p. 132-136, 1980a.

6 ODLER, I.; ADBUL-MAULA,S. Effect of mineralizers on the burning processo of Portland cement clinker, Part 2: Mode of action of mineralizerss. Zement-Kalk-Gips, Wiesbaden, n. 6, p. 278-282, 1980 b.

7 KNÖFEL, D. Modifying some properties of Portland cement clinker and Portland cement by means of $\mathrm{ZnO}$ and $\mathrm{ZnS}$. Zement-Kalk-Gips, Wiesbaden, v. 31, n. 3, p. 157-161, 1978. 
demonstrada por Arlinguie et al. (1982, 1990), que atribuem o fenômeno à formação do hidróxido de zinco e sua conversão a uma forma cristalina ao redor dos grãos anidros. Miller $(1976)^{8}$, segundo Maringolo (2001), registrou a formação de um composto intermediário complexo de zincato hidratado de cálcio $(\mathrm{CaZn} 2(\mathrm{OH}) 6.2 \mathrm{H} 2 \mathrm{O})$, que inibe a hidratação da alita.

Para os estudos de misturas de cimento com resíduos, o efeito da presença de Zn pode ser identificado pela norma NM9:2003 - Determinação dos tempos de pega de concretos e argamasas por meio de resistência à penetração. Porém algumas vezes ocorre um ressecamento superficial da pasta de cimento, o que pode mascarar o resultado. Recomenda-se realizar um ensaio de calorimetria. Vargas (2002) ressalta que o emprego do ensaio prescrito pela NBR 11581, para determinação de tempo de pega das pastas de cimento, não se mostra adequado, sugerindo o emprego de ensaios de determinação do calor de hidratação.

Deve-se levar em consideração a aplicação que se deseja para a matriz cimentícia com a utilização de resíduo com zinco, visto que dependendo de onde for usada, o retardamento da pega pode vir a ser benéfico.

A figura 8 ilustra detalhe do fluxograma, onde destaca-se a análise decorrente da presença de zinco.

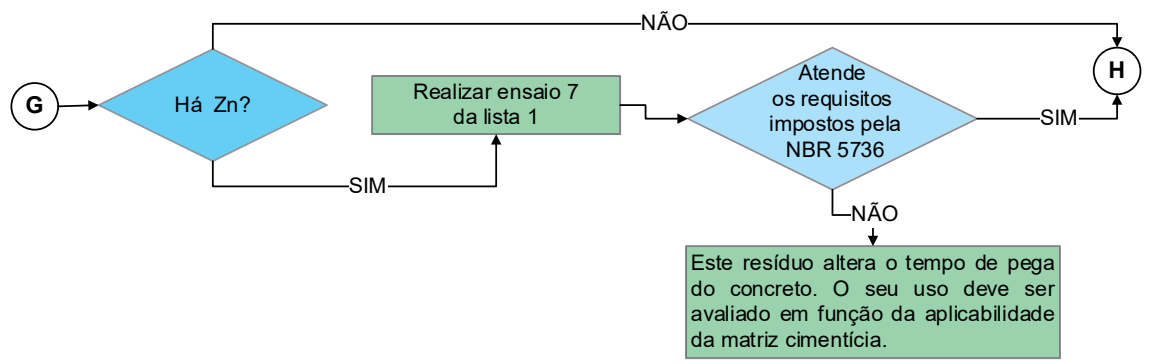

Figura 8. Detalhe do fluxograma, destacando-se a análise decorrente da presença de zinco.

8 MILLER, F. M.. Minor elements in cement clínquer. In: PCA Cement Chemist's Seminar, 1976. Proceedings... Portland Cement Association, Skokie, Illinois, USA, 1976. 


\subsubsection{Trióxido de Enxofre $\left(\mathrm{SO}_{3}\right)$}

No clínquer, o enxofre tem origem na matéria prima onde normalmente se apresenta na forma de sulfetos (pirita, marcassita), podendo também ser resultante de impureza do combustível (CENTURIONE, 1993). Quando na fabricação, causa problemas na formação do clínquer bem como leva à incorporação de sulfatos alcalinos ao produto formado. Conforme Duda $(1977)^{9}$, citado por Centurione (1993), a evolução das resistências mecânicas do cimento se reduz consideravelmente em presença de sulfatos alcalinos, além do risco elevado de ocorrência de fissuras por expansóes geradas após o endurecimento da matriz cimentícia.

Um ensaio de desempenho acelerado foi desenvolvido pelo Laboratoire Central de Ponts et des Chaussées (LCPC) em parceria com outras associaçóes para avaliar a durabilidade conjunta com relação à dosagem e ao aquecimento do concreto frente à formação da etringita tardia, seguida de expansão. $\mathrm{O}$ ensaio, além de avaliar a dosagem do concreto, determina a reatividade potencial na formação de etringita tardia, com combinação de parâmetros admissíveis para evitar o fenômeno (OLLIVIER; VICHOT, 2014).

No agregado, a determinação de sulfatos solúveis, bem como de cloretos e outros sais, pode ser realizada segundo a NBR 9917:2009.

A figura 9 ilustra detalhe do fluxograma, onde destaca-se a análise decorrente da presença de sulfatos.

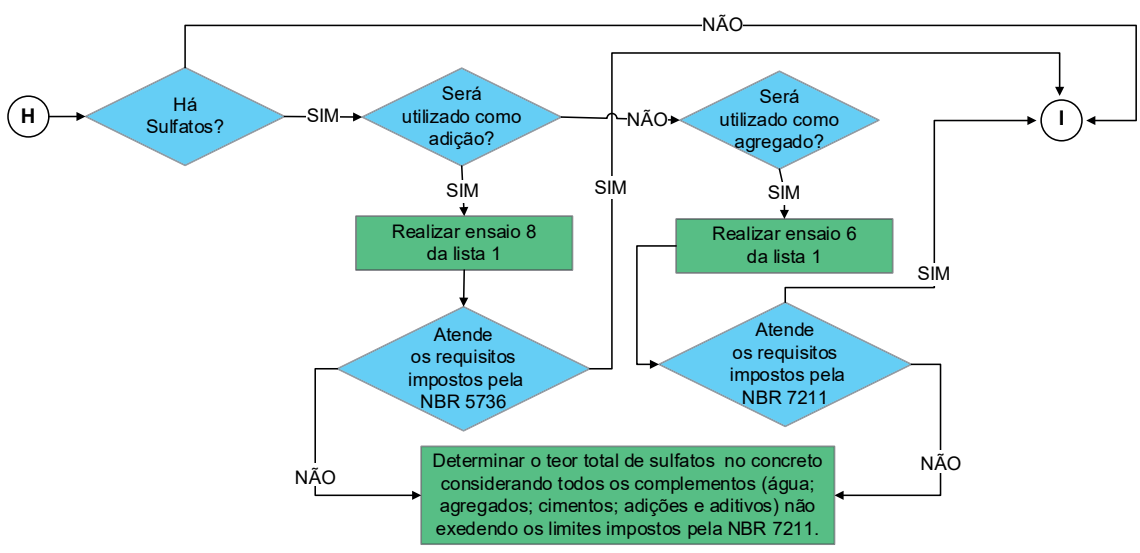

Figura 9. Detalhe do fluxograma, destacando-se a análise decorrente da presença de Sulfatos.

9 DUDA, W. H. Cemente data book. Berlin: Bauverlag Gmb. 1977. 


\subsubsection{7. Óxido de Ferro (FeO)}

O óxido de ferro é um material que pode ser encontrado em resíduos tais como as escórias de aciaria, corte de mármore e granito, entre outros.

Dependendo da fase em que este mineral se encontra pode gerar mecanismos de expansão, deteriorando a matriz produzida. Esta expansão é ocasionada devido à oxidação ou à corrosão do ferro metálico $\left(\mathrm{Fe}^{0}\right)$ presente em sua composição (MANCIO, 2001).

A expansão das escórias por oxidação do ferro ocorre principalmente devido à mudança do ferro do estado $\mathrm{Fe}^{+2}$ para o estado $\mathrm{Fe}^{+3}$, a partir de reaçóes com o oxigênio do ar (MANCIO, 2001 e MASUERO, 2001).

A expansão provocada pela oxidação do ferro metálico gera um aumento em volume que pode ser de até 600\% (MEHTA e MONTEIRO, 2013).

Para a detecção da expansão causada pelo óxido de ferro recomenda-se utilizar o ensaio EN 1744/98, por realizar a aceleração das reaçôes com vapor de água. É o que apresenta as melhores condiçôes para a verificação da expansão devida à oxidação do ferro (MANCIO, 2001).

Deve-se ressaltar que não são todas as fases deste mineral que irão desencadear os mecanismos de expansão. Sabe-se que o $\mathrm{Fe}_{2} \mathrm{O}_{3}$ é importante tanto para materiais considerados pozolânicos quanto para materias considerados cimentantes. A wustita é a fase que propicia as maiores expansões, uma vez que através de reaçóes de oxidação se transforma em compostos de maior volume, apesar da tendência de formar uma solução sólida com manganês e magnésio, devido a altos teores de ferro (SERSALE, 1986, citado por MASUERO et al. $2001)^{10}$.

A figura 10 ilustra detalhe do fluxograma, onde destaca-se a análise decorrente da presença de compostos a base de ferro.

10 SERSALE, R. et al. Chracterization and potencial uses of steel slag. Silicates Industriels, Bruxelles, v.51, p.163-170, 1986. 


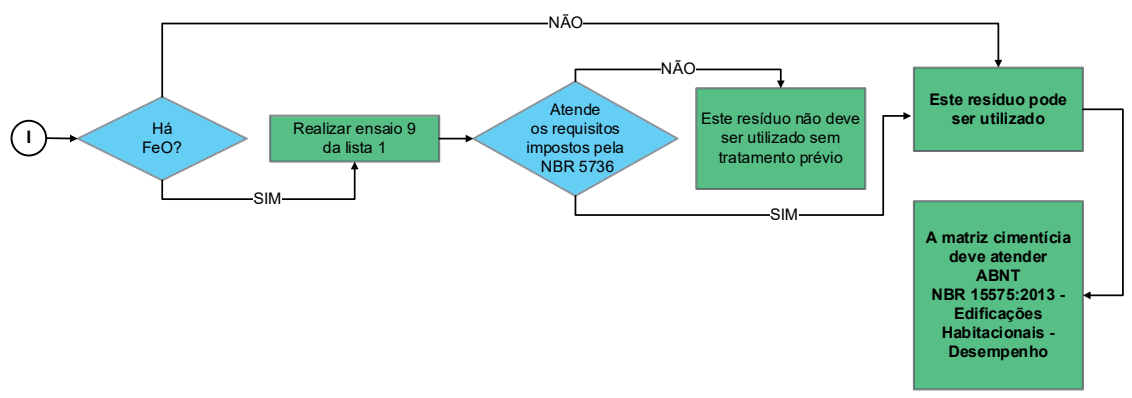

Figura 10. Detalhe do fluxograma, destacando-se a análise decorrente da presença de Óxido de Ferro.

\subsection{Etapa 2 - Fluxogramas}

A metodologia para a análise do potencial deletério de resíduos visando a sua utilização em matrizes cimentícias foi sistematizada na forma de fluxogramas (Figuras 11 a 14), através dos quais é possível avaliar o desempenho técnico do resíduo em função da sua classificação ambiental, e relacionar a composição química com a durabilidade.

O primeiro passo, considerando um resíduo qualquer, é a sua caracterização ambiental. Na sequência, as composiçóes química e mineralógica do resíduo em estudo são necessárias para a continuidade da investigação. A indicação da viabilidade ou não do uso do resíduo, na matriz cimentícia, é o resultado obtido ao final do fluxograma.

\subsubsection{Como Utilizar o Fluxograma}

Para iniciar a análise do resíduo, primeiramente é realizada a sua caracterização do ponto de vista ambiental e quanto ao risco à saúde pública, segundo o fluxograma que consta na NBR 10004:2004 (Figura 11). A classificação dos resíduos envolve a identificação do processo ou atividade que lhes deu origem e de seus constituintes e características e a comparação destes constituintes com listagens de resíduos e substâncias cujo impacto à saúde e ao meio ambiente é conhecido (NBR 10004:2004).

Logo, o primeiro questionamento é sobre a origem do resíduo, se este apresenta origem conhecida e consta no anexo A ou B da NBR 10004:2004, ou se não tem origem conhecida e apresenta alguma característica como 
inflamabilidade, corrosividade, reatividade, toxicidade ou patogenicidade. Neste caso o resíduo é considerado perigoso, isto é, apresenta risco à saúde pública e/ou risco ao meio ambiente. Aconselha-se que este tipo de resíduo náo seja utilizado. Entretanto, dependendo do tipo de periculosidade que o resíduo apresente, é possível que o mesmo esteja encapsulado ou solidificado e/ou estável. Neste caso, deve ser seguido o protocolo prescrito na NBR 10005 e 10006, ambas de 2004, que consiste na análise de lixiviação e solubilização do resíduo.

Se o resíduo não constar no anexo $\mathrm{A}$ e $\mathrm{B}$ e não apresentar nenhuma das características referidas, é considerado um resíduo não perigoso. Para saber se ele é considerado inerte ou não, é preciso analisar se o resíduo possui constituintes que são solúveis em concentraçóes superiores ao anexo $\mathrm{G}$. Se possuir, é considerado resíduo não-inerte, o que significa que pode ter propriedades, tais como: biodegradabilidade, combustibilidade ou solubilidade em água. Se o resíduo não apresentar concentração superior, ele é considerado resíduo inerte.

Quando o resíduo é classificado como não inerte ou inerte, prossegue-se com a caracterização deste. $\mathrm{Na}$ sequência, o resíduo é avaliado nos quesitos relacionados à sua composição química e possíveis efeitos deletérios, que podem se manifestar quando estes são incorporados em matrizes cimentícias. Para cada composto existe a indicação da realização de pelo menos um ensaio para detectar a alteração provocada pelo resíduo (Figuras 12 a 14).

O fluxograma está organizado inicialmente pela verificação quanto à presença de $\mathrm{CaO}_{\text {livre }}$. Em caso positivo, indica-se a realização do ensaio de "Determinação de expansibilidade Le Chatelier a frio (NBR 11582:2012)", conforme Quadro 1, e, se o resultado atender aos requisitos impostos pela norma se encaminha para a próxima análise, caso contrário, aconselha-se que o material não seja utilizado sem tratamento prévio, que pode ser a estabilização dos compostos a partir de reaçóes no tempo ou de modo acelerado.

A próxima análise é quanto ao $\mathrm{MgO}_{\text {livre }}$. Se existir este composto indica-se a realização do ensaio de "Determinação de expansibilidade Le Chatelier a quente” (NBR 11582:2012), conforme Quadro 1, e, se o resultado atender aos requisitos impostos pela norma, segue-se para a próxima análise. Caso não atenda aos requisitos, aconselha-se que o material não seja utilizado sem tratamento prévio, para a estabilização dos compostos. 
Após, questiona-se se há a presença de álcalis $\mathrm{K}_{2} \mathrm{O}$ e/ou $\mathrm{Na}_{2} \mathrm{O}$ e assim sucessivamente até o final dos fluxogramas propostos.

Caso o resíduo avaliado atenda todos os requisitos impostos no fluxograma, ao final do processo será considerado apto para ser utilizado. Na sequência, definidas as potencialidades e limitaçóes de uso do resíduo, são investigados os possíveis e mais promissores materiais que podem ser desenvolvidos com estes resíduos. Os novos materiais produzidos precisam, então, ser caracterizados do ponto de vista ambiental, mecânico e de durabilidade uma vez que os produtos que incorporam resíduos náo podem ter sua qualidade e durabilidade comprometida. Neste sentido, devem ser submetidos à avaliação segundo os requisitos da NBR 15575:2013 - Edificaçôes Habitacionais - Desempenho. Caso o material ou componente com o resíduo não atenda as especificações dos ensaios que estão sendo propostos, em qualquer dos itens avaliados, o seu uso, na forma proposta, passa a ser desaconselhado. 


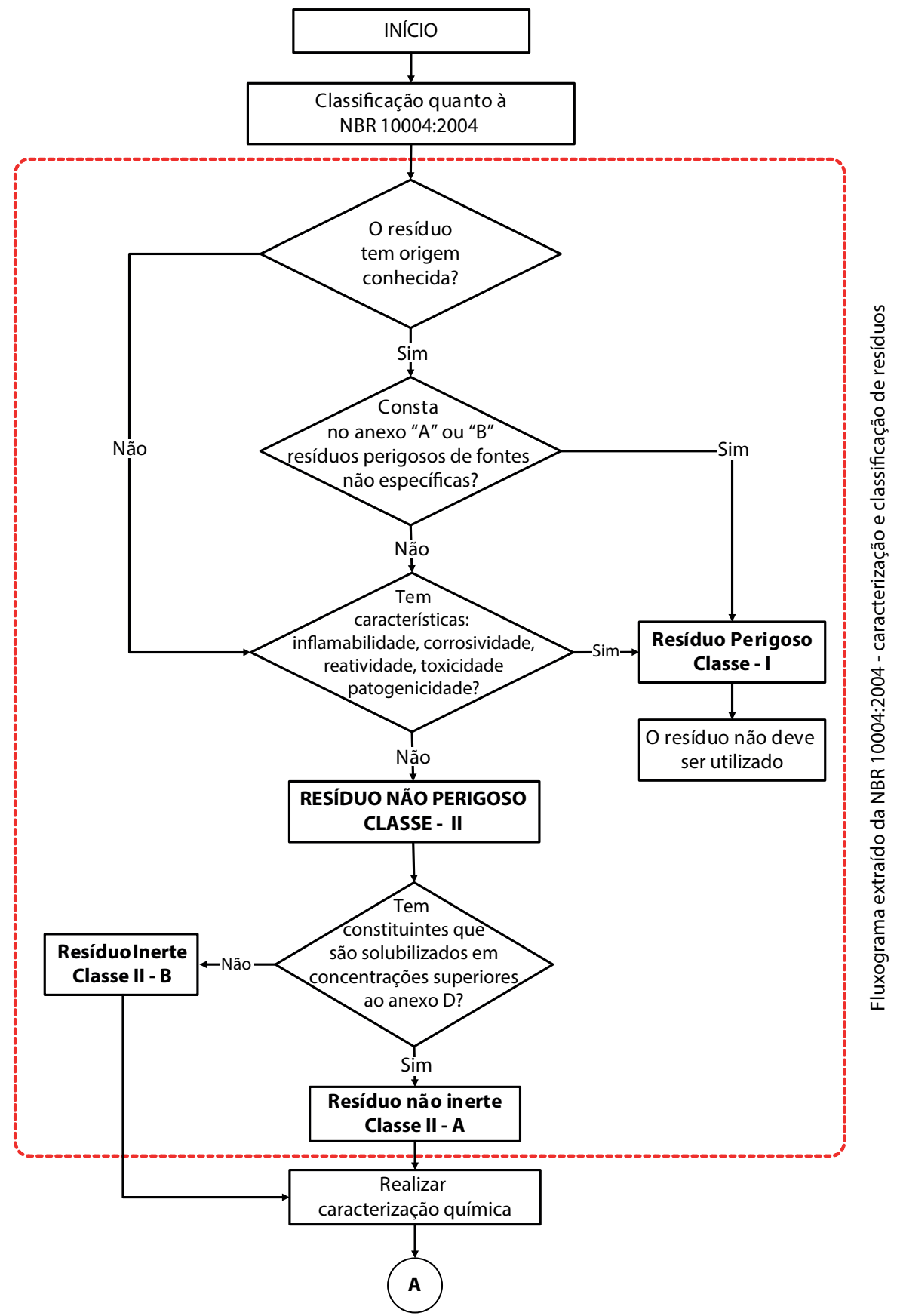

Figura 11. Fluxograma, parte 1- classificação ambiental conforme NBR 10004:2004. Fonte: NBR 10004:2004. 


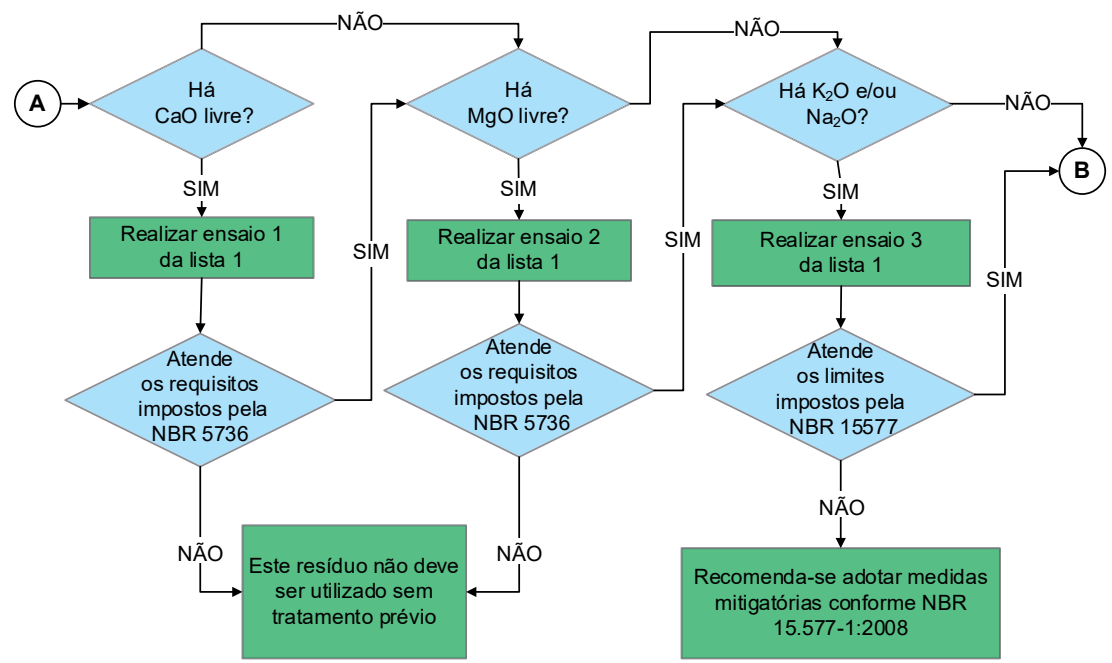

Figura 12. Fluxograma, parte 2 - Avaliação de possíveis efeitos deletérios em matriz cimentícia.

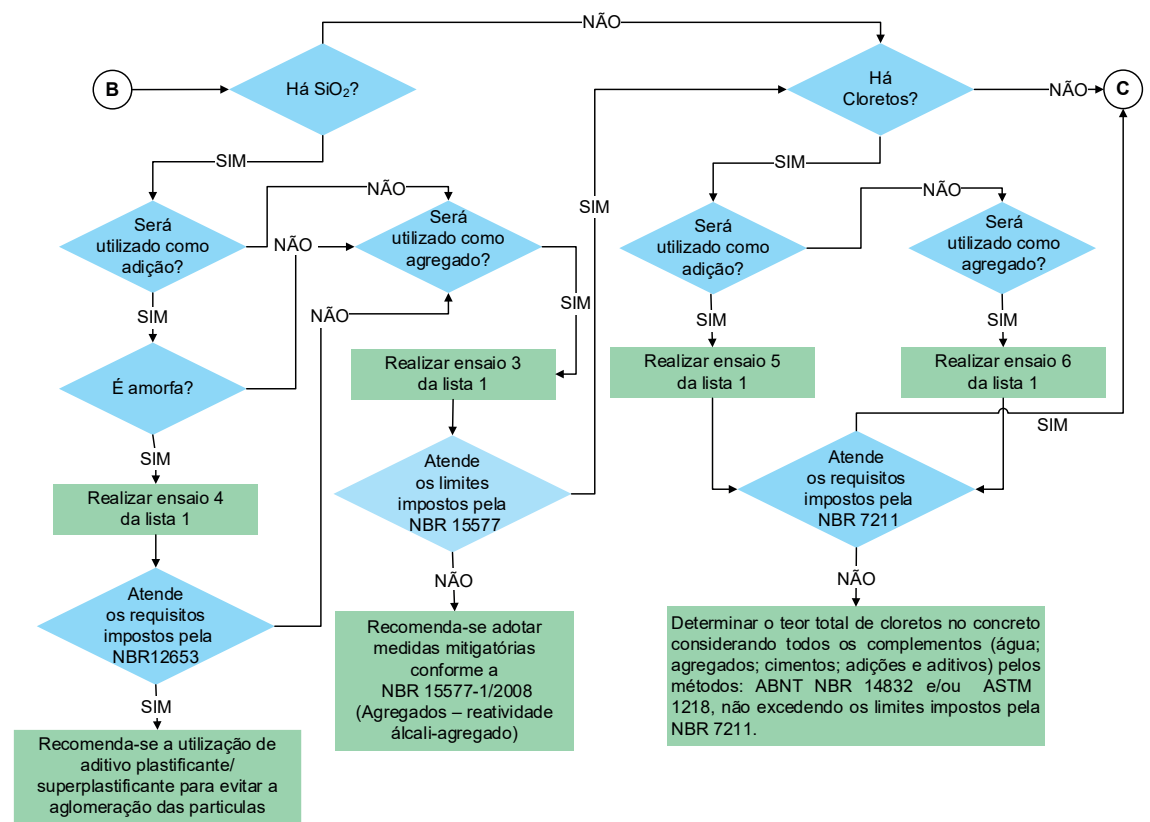

Figura 13. Fluxograma, parte 3 - Avaliação de possíveis efeitos deletérios em matriz cimentícia. 


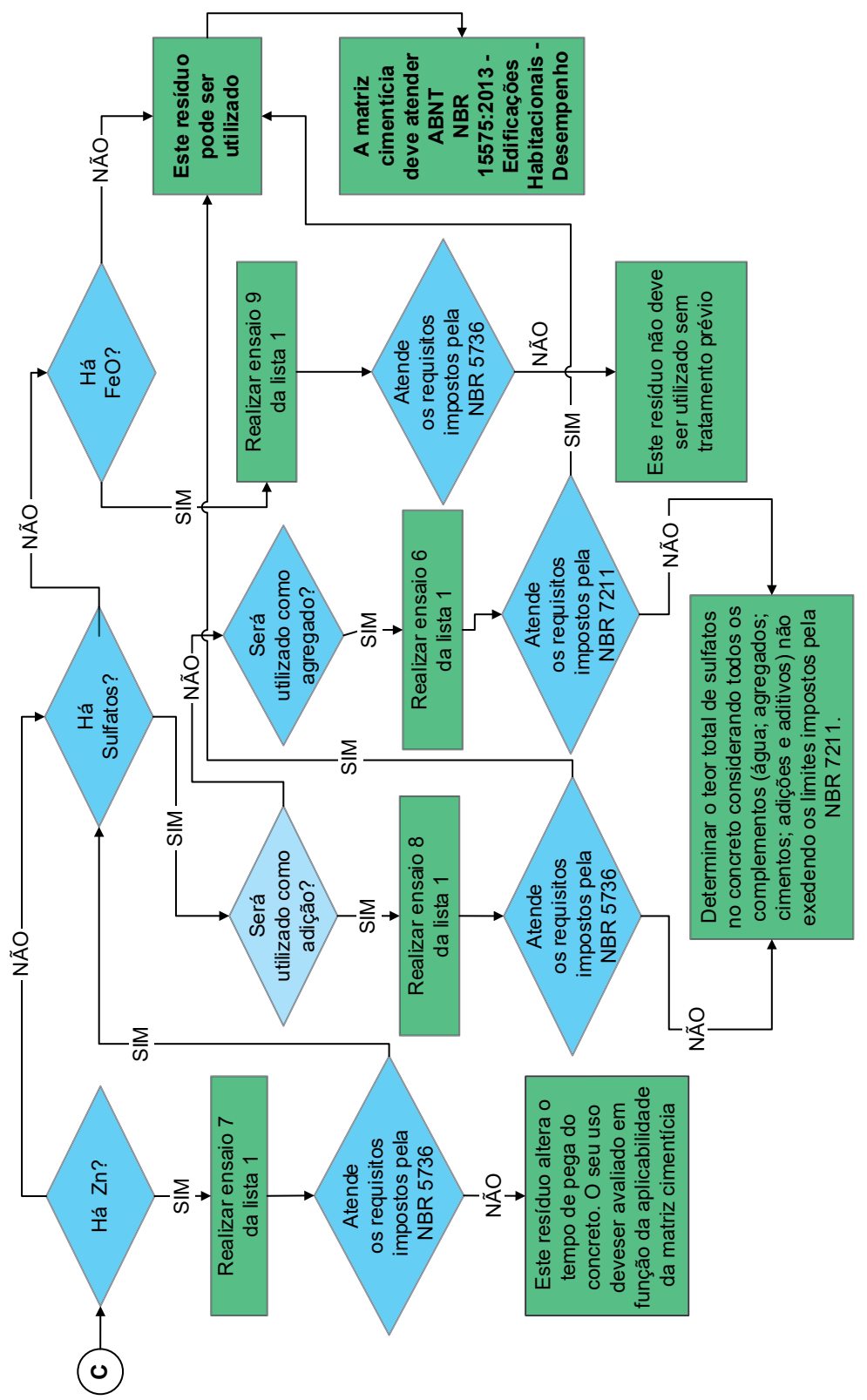

Figura 14. Fluxograma, parte 4 - Avaliação de possíveis efeitos deletérios em matriz cimentícia 
Quadro 1. Lista de ensaios recomendados para avaliação de resíduos.

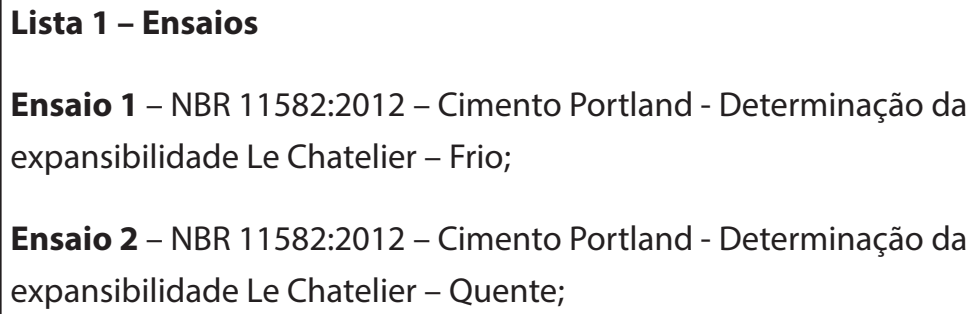

Ensaio 3 - NBR 15577-1:2008 - Agregados -Reatividade álcali-agregado. Parte 1: Guia para avaliação da reatividade potencial e medidas preventivas para uso de agregados em concreto;

Ensaio 4 - NBR 5751:2012 - Materiais pozolânicos - Determinação da atividade pozolânicas - Índice de atividade pozolânicas com cal - Métodos de ensaio. Ou NBR 5752: 2014 - Materiais pozolânicos - Determinação de índice de desempenho com cimento Portland aos 28 dias.

Ensaio 5 - NBR 14832:2002 - Cimento Portland e clínquer - Determinação de cloreto pelo método de íon seletivo.

Ensaio 6 - NBM 9917:2009 - Agregados para concreto - Determinação de sais, cloretos e sulfatos solúveis;

Ensaio 7 - NBR NM 9:2003 - Determinação dos tempos de pega por meio de resistência à penetração;

Ensaio 8 - NBR NM 16: 2012 - Cimento Portland - Análise química Determinação de anidrido sulfúrico.

Ensaio 9 - EN 1744-1:2009 - Tests for chemical properties of aggregates. 


\section{Validação da Metodologia: Resíduo de Escórias de Aciaria Elétrica Granulada (ACGRAN)}

O resíduo utilizado para a validação da metodologia proposta é uma escória de aciaria elétrica.

As escórias de aciaria são os principais resíduos gerados durante o processo de fabricação do aço, tanto em conversores a oxigênio, denominadas escórias de aciaria LD ou BOF, quanto em fornos elétricos a arco (FEA), denominadas escórias de aciária elétrica. Estima-se que a geração mundial de escórias de aciaria situe-se em torno de 65 milhóes de toneladas por ano. No Brasil, a geração de escória de aciaria é de aproximadamente 3,8 milhôes de toneladas por ano (http://www.acobrasil.org.br).

O principal obstáculo no que se refere à utilização das escórias de aciaria como material de construção civil é a sua instabilidade volumétrica (VIKLUND-WHITE; YE, 1999).

Os teores de óxido de cálcio $(\mathrm{CaO})$ livre e óxido de magnésio $(\mathrm{MgO})$ livre são os fatores mais importantes a serem considerados para a utilização da escória de aciaria como material de construção, uma vez que há um amplo consenso na literatura técnica de que estes compostos são os maiores responsáveis pelas características expansivas do material, em especial em escórias de aciaria LD (COOMARASAMY; WALZAK, 1995; SSTC, 1996; MORINO; IWATSUKI, 1999; LUXÁN et al., 2000; MOTZ; GEISELER, 2001; CHESNER et al., 2001).

Para escórias de aciaria elétrica, a instabilidade volumétrica está associada principalmente ao FeO (MANCIO, 2001; MASUERO, 2001), mas também pode ser decorrente ao $\mathrm{CaO}$ e $\mathrm{MgO}$.

Uma das formas de evitar a instabilidade volumétrica, é através do processo de resfriamento brusco (granulação). A aplicação da metodologia aqui apresentada refere-se a uma escória de aciaria elétrica que passou por esse processo. 


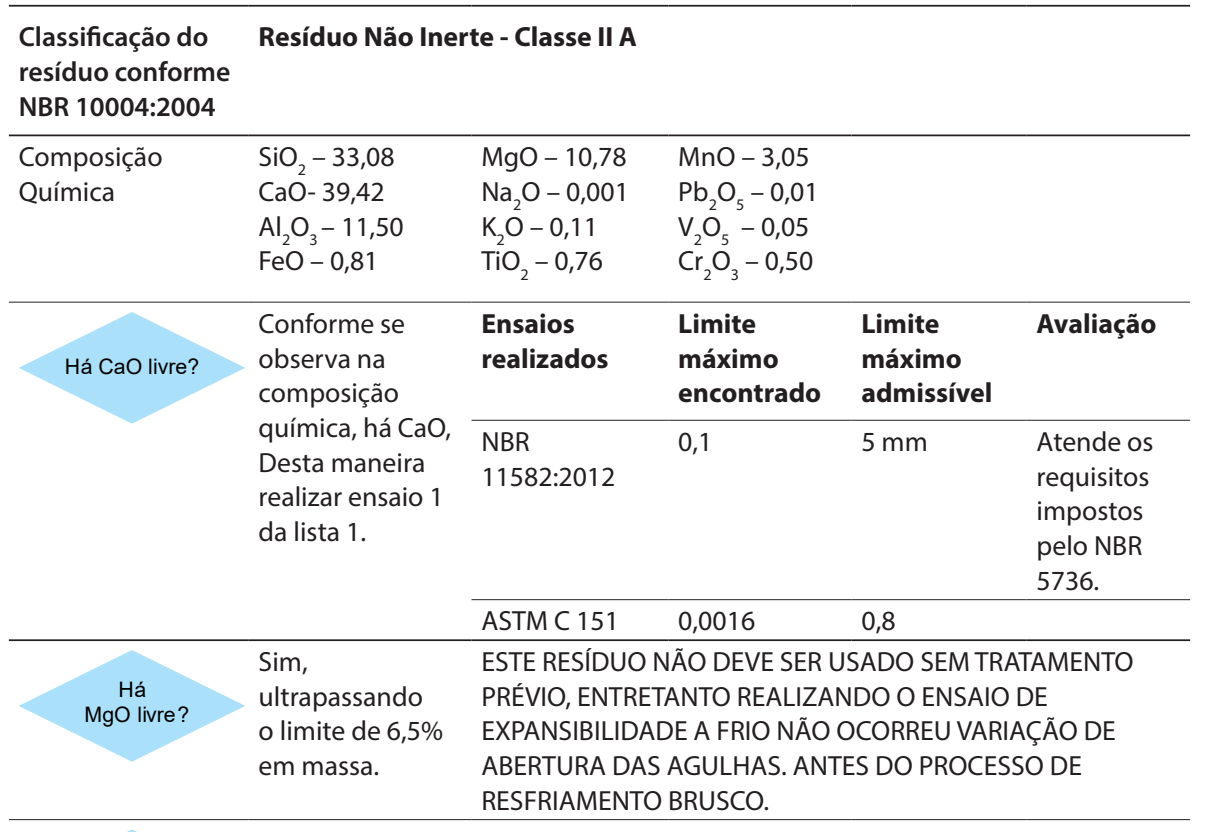

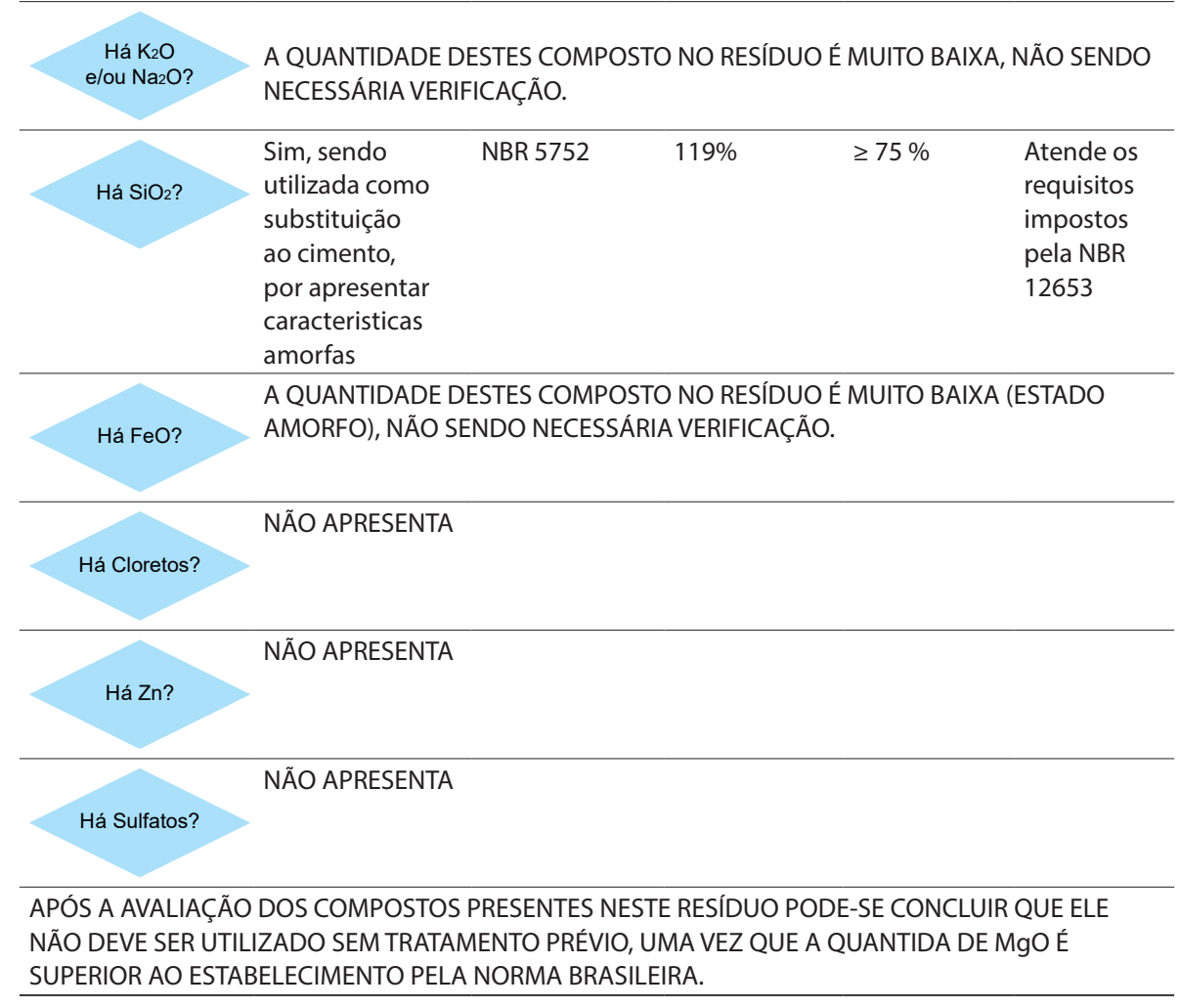




\subsection{Exemplo do Uso da Metodologia}

O resíduo utilizado para a validação da metodologia proposta é uma escória de aciaria elétrica que passou por um processo de resfriamento brusco, onde foi alterada a sua estrutura interna, passando de cristalina a amorfa.

\subsection{Avaliação do Resíduo}

Após a verificação do potencial deletério dos componentes da escória de aciaria elétrica, foi realizada uma caracterização complemente do ponto de vista físico, químico e ambiental, visando a utilizaçáo deste em matrízes de base cimentícia.

\begin{tabular}{|c|c|}
\hline $\begin{array}{l}\text { Ponto de vista } \\
\text { físico }\end{array}$ & $\begin{array}{l}\text { Massa Específica }\left(\mathrm{kg} / \mathrm{dm}^{3}\right)-2,90 \\
\text { Diâmetro médio }(\mu \mathrm{m})-4,83\end{array}$ \\
\hline \multirow[t]{2}{*}{ 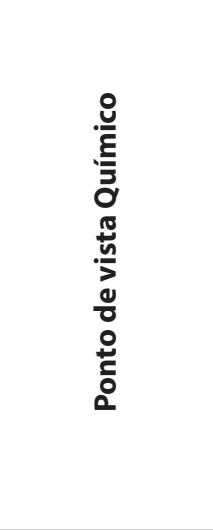 } & $\begin{array}{l}400 \\
225 \\
100 \\
25\end{array}$ \\
\hline & A partir da DFR observa-se que $c$ \\
\hline $\begin{array}{l}\text { Ponto de vista } \\
\text { Ambiental }\end{array}$ & Resíduo Não Inerte - Classe II \\
\hline
\end{tabular}

\subsection{Avaliação do Composto Cimentício}

O resíduo foi incorporado em argamassas como substituição ao cimento, uma vez que de acordo com as características apresentadas no item 3 e no subitem 3.1, não apresentaram nenhuma restrição quanto ao seu emprego. Desta maneira, foram testados os teores de substituição de 10\%, 30\% e $50 \%$ do cimento, em volume, pelo resíduo, avaliando a influência destas nas propriedades mecânicas (resistência à compressão) e durabilidade (Absorção de água por imersão e coeficientes de difusão) e do ponto de vista ambiental 
das matrizes de base cimentícia. A seguir são apresentados os resultados obtidos nos ensaios realizados. Na Figura 15, é possível observar que a incorporação do resíduo na matriz de base cimentícia é satisfatória quanto à resistência à compressão, uma vez que a substituição de até $50 \%$ não provocou alteraçóes nesta propriedade. Na Figura 16, observa-se que a utilização do resíduo reduz a absorção de água, o que é benéfico para as argamassas. A Figura 16 b mostra, de modo geral, que o resíduo auxiliou na redução do coeficiente de difusão. Os quadros 2 e 3 tratam sobre a avaliação ambiental do resíduo inserido na argamassa, sendo que o traço utilizado para análise foi o 1:1,5 com 50\% de teor de substituição de cimento pelo resíduo, em volume. Neste, é possível observar que tanto a argamassa de referência quanto a argamassa com o resíduo são consideradas não perigosas pelo ensaio de lixiviação (Quadro 2). Quanto ao ensaio de solubilização (Quadro 3), observa-se que a argamassa de referência é considerada não inerte e a argamassa com o resíduo é considerada inerte.

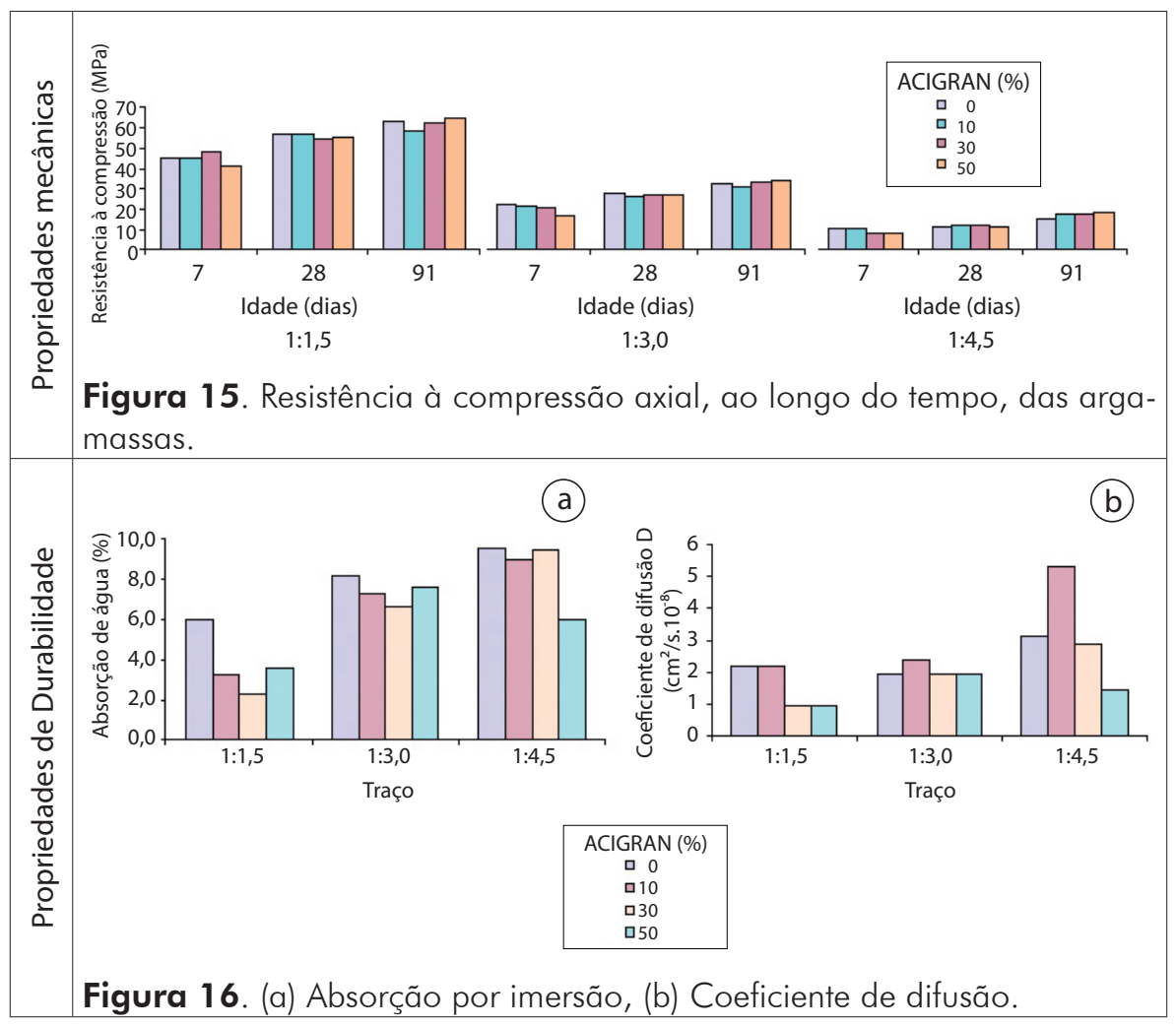




\begin{tabular}{|c|c|c|c|c|}
\hline & $\begin{array}{l}\text { Quadro 2.R } \\
\text { das argamas }\end{array}$ & $\begin{array}{l}\text { esultados e limites } \\
\text { as sem e com esc }\end{array}$ & $\begin{array}{l}\text { haximos admissiveis } \\
\text { rias }\end{array}$ & o ensaio de lixiviacao \\
\hline & Elementos & LIXIVIAÇÃO & & \\
\hline & & $\begin{array}{l}\text { Referência }(1: 1,5) \\
\text { Quantidade }\end{array}$ & $\begin{array}{l}\text { Traço 1:1,5 -50\% } \\
\text { AciGran Quantidade }\end{array}$ & $\begin{array}{l}\text { Limite máximo } \\
\text { (mg/l) NBR } 10005\end{array}$ \\
\hline & Arsênio & - & & 5 \\
\hline & Bário & $<1$ & $<1$ & 100,0 \\
\hline & Cádmio & 0,03 & 0,02 & 0,5 \\
\hline & Chumbo & 0,14 & 0,1 & 5 \\
\hline & Cromo & 0,10 & 0,18 & 5 \\
\hline & Fluoreto & 0,87 & 1,8 & 50,0 \\
\hline & Mercúrio & & & 0,1 \\
\hline & Prata & 0,02 & 0,01 & 5,0 \\
\hline & Selênio & & & 1,0 \\
\hline 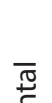 & $\begin{array}{l}\text { Quadro } 3 . \\
\text { solubilizacao }\end{array}$ & $\begin{array}{l}\text { Resultados e li } \\
\text { das argamassas }\end{array}$ & $\begin{array}{l}\text { ites maximos adm } \\
m \text { e com escorias } A\end{array}$ & $\begin{array}{l}\text { siveis do ensio de } \\
\text { IGRAN }\end{array}$ \\
\hline$\frac{\bar{\omega}}{\overline{0}}$ & Elementos & SOLUBILIZAÇÃO & & \\
\hline 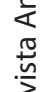 & & $\begin{array}{l}\text { Referência }(1: 1,5) \\
\text { Quantidade }\end{array}$ & $\begin{array}{l}\text { Traço 1:1,5-50\% } \\
\text { AciGran Quantidade }\end{array}$ & $\begin{array}{l}\text { Limite máximo (mg/l) } \\
\text { NBR } 10006\end{array}$ \\
\hline$\frac{\pi}{0}$ & Arsênio & - & - & 0,05 \\
\hline$\stackrel{0}{\stackrel{2}{\rightleftarrows}}$ & Aluminio & $<0,20$ & $<0,20$ & 0,20 \\
\hline & Bário & $<1,00$ & $<1,00$ & 1,00 \\
\hline & Cádmio & - & - & 0,005 \\
\hline & Chumbo & $<0,05$ & $<0,05$ & 0,05 \\
\hline & Cianeto & - & - & 0,10 \\
\hline & Cloreto & 1,40 & 2,10 & 250,00 \\
\hline & Cobre & $<0,02$ & $<0,02$ & 1,0 \\
\hline & Cromo & 0,04 & 0,04 & 0,05 \\
\hline & Dureza & 1258 & 442 & 500 \\
\hline & Fenol & - & - & 0,001 \\
\hline & Ferro & $<0,03$ & $<0,03$ & 0,30 \\
\hline & Fluoreto & 0,03 & 0,16 & 1,50 \\
\hline & Manganês & 0,03 & 0,03 & 0,10 \\
\hline & Mercúrio & - & - & 0,001 \\
\hline & Nitratos & - & - & 10,00 \\
\hline & Prata & $<0,01$ & $<0,01$ & - \\
\hline & Selênio & - & - & - \\
\hline & Sódio & 57 & 88 & 200 \\
\hline & Sulfatos & 250 & 109 & 400 \\
\hline & Sulfactantes & - & - & 0,20 \\
\hline & Zinco & $<0,01$ & $<0,01$ & 5,00 \\
\hline
\end{tabular}


O resíduo apresentou respostas satisfatórias em todos os quesitos analisados, indicando assim que é possível utilizá-lo na confecção de elementos ou componente de base cimentícia.

\section{Considerações Finais}

Diante da crescente preocupação com questóes ambientais e o grande volume de resíduos gerados, o reaproveitamento de produtos, subprodutos e resíduos agrícolas, industriais e da construção civil é fundamental para reduzir os impactos ambientais gerados pela sociedade. Dada como uma das alternativas para este problema, a incorporaçáo destes resíduos pela construção civil, em matrizes cimentícias, pode ser realizada desde que seja feita previamente uma análise da sua interferência nas propriedades mecânicas e na durabilidade das estruturas. Atualmente, o Brasil não conta com uma norma específica que regulamente quanto à utilização de resíduos em matrizes cimentícias. Neste contexto, este trabalho apresentou a sistematização de uma metodologia para verificar o potencial deletério de determinados resíduos quando incorporados em matrizes cimentícias.

A metodologia de avaliação proposta é apresentada com o intuito de auxiliar e padronizar a verificação do potencial deletério oriundo da incorporaçáo de resíduos em argamassas e concretos. Além disto, deve ser encarada como pioneira, servindo de contribuição para estudos mais aprofundados e elaborados sobre o assunto. Salienta-se que a metodologia apresentada náo contempla a contaminação do resíduo (que pode ocorrer no estoque e durante o transporte) e considera somente como potencial deletério os principais compostos químicos do resíduo (obtidos a partir de revisão bibliográfica). No entanto, outros elementos químicos com potenciais deletérios, não comuns, podem estar presentes nos resíduos em função da variação na sua composição, que não são considerados neste trabalho.

Vale ressaltar que todas as matrizes cimentícias que empregam resíduos devem atender a Norma de Desempenho (NBR 15.575), levando em consideração a aplicação que se deseja para elas. 


\section{Referências Bibliográficas}

ABREU, A. G. Efeito das adiçóes minerais na resistividade elétrica de concretos Convencionais. Porto Alegre, 1998. Dissertação (Mestrado em Engenharia Civil). Programa de PósGraduação em Engenharia Civil- Universidade Federal do Rio Grande do Sul. 1998.

ABREU, A. G. Estudo da corrosão da armadura induzida por carbonatação em concretos com altos teores de cinza volante. 2004. Tese (Doutorado em Engenharia), Programa de Pós-Graduação em Engenharia Civil - PPGEC, Universidade Federal do Rio Grande do Sul, 2004.

AMERICAN SOCIETY FOR TESTING AND MATERIALS. ASTM C-1260/14: Standard test method for potential alkali reactivity of aggregates (mortar-bar method). Philadelphia, 2014. Section 4 (Construction), (Concrete and Aggregates).

AMERICAN SOCIETY FOR TESTING AND MATERIALS. ASTM C-1206/10: Standard test Methos for Plutonium by Iron (II)/ Chromium (VI) Amperometric Titration (Withdrawn 2015). Philadelphia, 2010.

AMERICAN SOCIETY FOR TESTING AND MATERIALS. ASTM C-1293/08: Standard test Methos for Determination of Length Change of Concrete Due to Alkali-Silica Reaction. Philadelphia, 2008.

AMERICAN SOCIETY FOR TESTING AND MATERIALS. ASTM C-1260/14: Standard test method for potential alkali reactivity of aggregates (mortar-bar method). Philadelphia, 2014. Section 4 (Construction), (Concrete and Aggregates).

AMERICAN SOCIETY FOR TESTING AND MATERIALS. ASTM C-227/10a: Standard test method for potential alkali reactivity of cement-aggregate combinations (mortarbar method). Philadelphia, 2010. Section 4 (Construction), (Concrete and Aggregates).

AMERICAN SOCIETY FOR TESTING AND MATERIALS. ASTM C-295/08: Standard for guide of aggregates for concrete. Philadelphia, 2008. Section 4 (Construction), (Concrete and Aggregates).

ASSOCIAÇÃO BRASILEIRA DE NORMAS TÉCNICAS. NBR 10004:2004. Resíduos sólidos - Classificação. Rio de Janeiro: ABNT, 2004.

ASSOCIAÇÃO BRASILEIRA DE NORMAS TÉCNICAS. NBR 10005:2004. Procedimento para obtenção de extrato lixiviado de resíduos sólidos - Classificaçáo. Rio de Janeiro: ABNT, 2004.

ASSOCIAÇÃO BRASILEIRA DE NORMAS TÉCNICAS. NBR 10006:2004. Procedimento para obtenção de extrato solubilizado de resíduos sólidos - Classificação. Rio de Janeiro: ABNT, 2004.

ASSOCIAÇÃO BRASILEIRA DE NORMAS TÉCNICAS. NBR 11582:2012. Cimento Portland - Determinação da expansibilidade Le Chatelier. Rio de Janeiro: ABNT, 2012.

ASSOCIAÇÃO BRASILEIRA DE NORMAS TÉCNICAS. NBR 15575: 2013. Edificaçôes Habitacionais - Desempenho. Rio de Janeiro, 2013. 
ASSOCIAÇÃO BRASILEIRA DE NORMAS TÉCNICAS. NBR 15577- 1: 2008 Agregados - Reação Álcali-Agregado. Parte 1: Guia para avaliação da reatividade potencial e medidas preventivas para uso de agregados em concreto. Rio de Janeiro, 2008.

ASSOCIAÇÃO BRASILEIRA DE NORMAS TÉCNICAS. NBR 15577- 3: 2008 Agregados - Reação Álcali-Agregado. Parte 3: Análise petrográfica para verificação da potencialidade reativa de agregados em presença de álcalis do concreto. Rio de Janeiro, 2008.

ASSOCIAÇÃO BRASILEIRA DE NORMAS TÉCNICAS. NBR 15577- 4: 2008 agregados - reação álcali-agregado. Parte 4: determinação da expansão em barras de argamassa pelo método acelerado. Rio de Janeiro, 2008.

ASSOCIAÇÃO BRASILEIRA DE NORMAS TÉCNICAS. NBR 15577- 5: 2008: Agregados - Reatividade álcali-agregado. Parte 5: Determinação da mitigação da expansão em barras de argamassa pelo método acelerado Rio de Janeiro, 2008.

ASSOCIAÇÃO BRASILEIRA DE NORMAS TÉCNICAS. NBR 5736:1991. Cimento Portland pozolânico. Rio de Janeiro, 1991.

ASSOCIAÇÃO BRASILEIRA DE NORMAS TÉCNICAS. NBR 5751:2012. Materiais pozolânicos - Determinação da atividade pozolânicas - Índice de atividade pozolânicas com cal - Métodos de ensaio. Rio de Janeiro, 2012.

ASSOCIAÇÃO BRASILEIRA DE NORMAS TÉCNICAS. NBR 5752: 2014. Materiais pozolânicos - Determinação de índice de desempenho com cimento Portland aos 28 dias. Rio de Janeiro, 2014.

ASSOCIAÇÃO BRASILEIRA DE NORMAS TÉCNICAS. NBR 5752:2012. Materiais pozolânicos — Determinação do índice de desempenho com cimento Portland aos 28 dias. Rio de Janeiro, 2012.

ASSOCIAÇÃO BRASILEIRA DE NORMAS TÉCNICAS. NBR 6118:2014. Projeto de estruturas de concreto - Procedimento. Rio de Janeiro, 20014.

ASSOCIAÇÃO BRASILEIRA DE NORMAS TÉCNICAS. NBR 7211:2009: agregados para concreto - especificação. Rio de Janeiro, 2009d.

ASSOCIAÇÃO BRASILEIRA DE NORMAS TÉCNICAS. NBR 7389-1:2009. Agregados - Análise petrográfica de agregado para concreto. Parte 2: Agregado graúdo. Rio de Janeiro: ABNT, 2009.

ASSOCIAÇÃO BRASILEIRA DE NORMAS TÉCNICAS. NBR 9917:2009. Agregados para concreto - Determinação de sais, cloretos e sulfatos solúveis. Rio de Janeiro: ABNT, 2009.

ASSOCIAÇÃO BRASILEIRA DE NORMAS TÉCNICAS. NBR 12653:2014. Materiais Pozolânicas - Requisitos. Rio de Janeiro: ABNT, 2014.

ASSOCIAÇÃO BRASILEIRA DE NORMAS TÉCNICAS. NBR 14832:2002. Cimento Portland e clínquer - Determinação de cloreto pelo método do íon seletivo. Rio de Janeiro: ABNT, 2002. 
ASSOCIAÇÃO BRASILEIRA DE NORMAS TÉCNICAS. NM 14:2012. Cimento Portland - Análise química - Método de arbitragem para a determinação de dióxido de silício, óxido de férrico, óxido de alumínio, óxido de cálcio e óxido de magnésio. Rio de Janeiro: ABNT, 2012.

ASSOCIAÇÃO BRASILEIRA DE NORMAS TÉCNICAS. NM 16:2012. Cimento Portland - Análise química - Determinação de anidrido sulfúrico. Rio de Janeiro: ABNT, 2012.

ASSOCIAÇÃO BRASILEIRA DE NORMAS TÉCNICAS. NM 17:2012. Cimento Portland - Análise química - Método de arbitragem para a determinação de óxido de sódio e óxido de potássio por fotometria de chama. Rio de Janeiro: ABNT, 2012.

ASSOCIAÇÃO BRASILEIRA DE NORMAS TÉCNICAS. NM 9:2003. Concreto e argamassa - Determinação dos tempos de pega por meio de resistência à penetração. Rio de Janeiro: ABNT, 2003.

BARATA, M. S. Concreto de alto desempenho no estado do Pará: Estudo de viabilidade técnica e econômica de produção de concreto de alto desempenho com os materiais disponíveis em Belém através do emprego de adiçóes de sílica ativa e metacaulin. Porto Alegre, 1998. Dissertação (Mestrado em Engenharia Civil), Programa de Pós-Graduação em Engenharia Civil- Universidade Federal do Rio Grande do Sul. 1998.

BREHM, F. A. Adição de óxido de zinco a pastas de cimento visando à reciclagem de pós de aciaria elétrica na construção civil. 2004. Tese (Doutorado em Engenharia de Minas, Metalúrgica e de Materiais), Programa de Pós-Graduação em Engenharia de Minas, Metalúrgica e de Materiais, Universidade Federal do Rio Grande do Sul, 2004.

BRITISH STANDARD. BS EN 1744-1:2009 - Tests for chemical properties of aggregates - Part I, 2009.

CASSA, S. B.l. A influência da adição de cinza de casca de arroz na resistência de concretos a àcidos. 2000. 128 f. Dissertação (Mestrado em Engenharia), Programa de Pós-Graduação em Engenharia Civil - PPGEC, Universidade Federal do Rio Grande do Sul, 2000.

CENTURIONE, S. L. Influência das Características das Matérias-Primas no Processo de Sinterização do Clínquer Portland. 154 f. São Paulo, 1993. Dissertação (Mestrado em Engenharia Civil) - Instituto de Geociências, Universidade de São Paulo, São Paulo, 1993.

CHIARO, S. X.; PETRY, N. S.; TIECHER, F.; B.; C.; KIRCHHEIM, A. P. Avaliação da potencialidade de desenvolvimento da reaçấo álcali-agregado de agregados oriundos de resíduos de ágata. In: XII Congreso Latinoamericano de Patología de la Construcción y XIV Congreso de Control de Calidad en la Construcción CONPAT-Colombia, 2013, Cartagena. XII Congreso Latinoamericano de Patología de la Construcción y XIV Congreso de Control de Calidad en la Construcción CONPAT-Colombia, 2013.

CORDEIRO, L. N. P. Análise dos parâmetros principais que regem a variabilidade dos concretos produzidos com agregado graúdo reciclado de concreto (AGRC). 2013. Tese (Doutorado em Engenharia Civil), Programa de Pós-Graduação em Engenharia Civil PPGEC, Universidade Federal do Rio Grande do Sul, 2013. 
CURUTCHET, B. S. S. Levantamento de resíduos de produção agro-industriais e seu potencial de utilização na indústria da construção. 1998. 133 f. Dissertação (Mestrado em Engenharia Civil), Programa de Pós-Graduação em Engenharia Civil - PPGEC, Universidade Federal do Rio Grande do Sul, 1998.

DE PAULA, M. O.; TINOCO, I. F.F.; RODRIGUES, C. S.; SILVA, E. N.; SOUZA, C.F.; Avaliação da atividade pozolânica da cinza de bagaço de cana-de-açúcar. Engenharia na Agricultura, Viçosa, MG, V.17, n.1, p.15-20, jan.-fev., 2009.

DELLA, V. P.; HOTZA, D.; JUNKES, J.A.; OLIVEIRA, A.P.N. Estudo comparativo entre sílica obtida por lixívia ácida da casca de arroz e sílica obtida por tratamento térmico da cinza de casca de arroz. Química Nova. v. 29, n. 6, p. 1175-1179, 2006.

FRÍAS, M.; VILLAR, E.; SAVASTANO Jr., H. Brazilian sugar cane bagasse ashes from the cogeneration industry as active pozzolans for cement manufacture. Cement \& Concrete Composites, v. 33, p. 490-496, 2011.

GEYER, A. Contribuição ao estudo da disposição final e aproveitamento da conza de lodo de estaçóes de tratamento de esgotos sanitários como adiçáo ao concreto. 2001. Tese (Doutorado em Engenharia), Programa de Pós-Graduação em Engenharia Civil - PPGEC, Universidade Federal do Rio Grande do Sul, 2001.

GEYER, R. T. Estudo sobre a potencialidade de uso das escórias de aciaria como adição ao concreto. 2001. Tese (Doutorado em Engenharia Mecânica), Programa de Pós-Graduação em Engenharia Mecânica, Universidade Federal do Rio Grande do Sul, 2001.

GIORDANI, C. Viabilidade técnica do uso de resíduos do beneficiamento de arenito como substituição do agregado miúdo em argamassas. 2014. 126 f. Trabalho de conclusão de curso (Graduação em Engenharia Civil) - Universidade Federal do Rio Grande do Sul, Porto Alegre, 2014.

GONÇALVES, J. P. Utilização do resíduo de corte de granito (RCG) como adiçáo para produção de concretos. 2000. 135f. Dissertação (Mestrado em Engenharia) - Núcleo Orientado para Inovação das Edificaçóes, Universidade Federal do Rio Grande do Sul, Porto Alegre.

GONÇALVES, J. P; MOURA, W. A.; DAL MOLIN, D. C. C. Avaliação da influência da utilização do resíduo de corte de granito (RCG), como adição, em propriedades mecânicas do concreto. Ambiente Construído, Porto Alegre, v. 2, n. 1, p. 53-68, jan.mar. 2002.

GUMIERI, A. G. Estudo da viabilidade técnica da utilização de escórias de aciaria do processo LD como adição em cimentos. Tese (doutorado). 2002. 251f. Núcleo Orientado para Inovação das Edificaçóes, Universidade Federal do Rio Grande do Sul, Porto Alegre.

HOFFMANN, A. T. Influência da adição de sílica ativa, relação água/aglomerante, temperatura e tempo de cura no coeficiente de difusão de cloretos em concretos. Porto Alegre, Dissertação no Programa de Pós-Graduação em Engenharia Civil- Universidade Federal do Rio Grande do Sul. 2001. 
JOHN, V. M. Aproveitamento de resíduos sólidos como materiais de construção. In: Carneiro, A. P., Brum, I. A. S., Cassa, J. C.S. (ORG). Reciclagem de resíduo para a produção de materiais de construção. Projeto resíduo bom. Salvador: Caixa Econômica Federal. 2001.

JOHN, V. M.; ZORDAN, S. E. Research \& development methodology for recycling residues as building materials - a proposal. Waste Management (Elmsford), Londres, v. 21, p. 213219, 2001.

KULAKOWSKI, M. P. Contribuição ao estudo da carbonatação em concretos e argamassas compostos com adição de sílica ativa. Porto Alegre, 2002. Tese (Doutorado em Engenharia) Programa de Pós-Graduação em Engenharia de Minas, Metalúrgica e de Materiais PPGEM, Universidade Federal do Rio Grande do Sul, 2002.

LEITE, M. B. Avaliação de propriedades mecânicas de concretos produzidos com agregados reciclados de resíduos de construção e demolição. 2001. 290p. Tese (Doutorado em Engenharia). Programa de Pós-Graduação em Engenharia Civil. Universidade Federal do Rio Grande do Sul, Porto Alegre, 2001.

MANCIO, M. Contribuição ao estudo do fenômeno da instabilidade volumétrica das escórias de aciaria elétrica. 2001. 0 f. Dissertação (Mestrado em Engenharia), Programa de PósGraduação em Engenharia Civil - PPGEC, Universidade Federal do Rio Grande do Sul, 2001.

MARINGOLO, V. Clinquer Co-Processado: produto de tecnologia integrada para sustentabilidade e competitividade da indústria de cimento. 174 f. São Paulo, 2001. Tese (Doutorado em Mineralogia e Petrologia) - Programa de Pós-Graduação em Mineralogia e Petrologia, Universidade de São Paulo, São Paulo, 2001.

MARTINEZ, J. D.; VÁSQUEZ, T. G. P.; JUNKES, J. A.; HOTZA, D.; Caracterização de cinza obtida por combustão de casca de arroz em reator de leito fluidizado. Química Nova, vol. 32, No5, p.1110-1114, 2009.

MASUERO, A. B. Estabilização das Escórias de Aciaria Elétrica com Vistas a sua Utilização como Substituição ao Cimento. 2001. 268 f. Tese (Doutorado em Engenharia) - Programa de Pós-Graduação em Engenharia de Minas, Metalúrgica e Materiais, Universidade Federal do Rio Grande do Sul, Porto Alegre, 2001.

MASUERO, A. B.; VILELA, A. C.; DAL MOLIN, D. Emprego de escórias de aciaria elétrica como adição a concretos. Revista ambiente construído, Porto Alegre, v. 4, n. 2, p. 57-81, abr./jun. ISSN 1415-8876, 2004.

MEHTA, P. K.; MONTEIRO, P. J. M. Concreto: estrutura, propriedades e materiais. São Paulo: Pini, 2014.

MOURA, W. A. Utilização de Escória de Cobre como Adição e como Agregado Miúdo para Concreto. 2000. 207 f. Tese (Doutorado em Engenharia) - Programa de Pós-Graduação em Engenharia Civil, Universidade Federal do Rio Grande do Sul, Porto Alegre, 2000.

MOURA.A. W. Utilização de escória de cobre como adição e como agregado miúdo para concreto. Tese (Doutorado) - Escola de Engenharia da Universidade Federal do Rio Grande do Sul. Porto Alegre, 2000. 232p. 
NEVES, G.; PATRICIO, S. M. R.; FERREIRA, H. C.; SILVA, M.C.; Utilização de residuos da serragem de granitos para a confecçâo de tijolos cerâmicos. In: 43 Congresso Brasileiro de Cerâmica. Florianópolis/SC. 1999

OLLIVIER, J.-P.; VICHOT, A. (Ed.) Durabilidade do Concreto: Bases científicas para formulação de concretos duráveis de acordo com o meio ambiente. São Paulo: IBRACON, 2014

PAULON, V. A. Reação alcali-agregado em concreto. São Paulo, 1981. 114p. Dissertação (Mestrado), Universidade de São Paulo, Escola Politécnica.

PETRY, N. S.; Uso de resíduos de ágata como agregado em argamassas de cimento Portland branco. Dissertação (Mestrado) - Escola de Engenharia da Universidade Federal do Rio Grande do Sul. Porto Alegre, 2015. 178p.

POlESE, M. O.; CARREIRO, G. L.; SILVA, M. G.; SILVA, M. R. Caracterização Microestrutural da Escória de Aciaria. Revista Matéria, v.11, n 4, pp 554-454, ISSN 1517-7076, 2006.

POLISSENI, A. E. Estudo da viabilidade técnica da utilização de escória de aciaria elétrica micronizada como material cimentício. 2005. Tese (Doutorado em Engenharia), Programa de Pós-Graduação em Engenharia Civil - PPGEC, Universidade Federal do Rio Grande do Sul, 2005.

POUEY, M. T. F. Beneficiamento da cinza de casca de arroz residual com vistas à produção de cimento composto e/ou Pozolânico . Tese (Doutorado em Engenharia), Universidade Federal do Rio Grande do Sul, Porto Alegre, 2006.

RECENA, F. A. P. Método de dosagem de concreto pelo volume de pasta com emprego de cinza volante. Porto Alegre, 2011. Tese (Doutorado em Engenharia) - Programa de PósGraduação em Engenharia Civil - PPGEC, Universidade Federal do Rio Grande do Sul, 2011.

ROCHA, J. C., JOHN, V. M. Utilização de Resíduos na Construção Habitacional. 2003. In: Coletânea Habitare. Disponível em http://www.habitare.org.br/pdf/publicacoes/ arquivos/125.pdf

RODRIGUES, M.S. Caracterização de cinza residual da queima da casca do arroz para a produção de argamassas. 2008. 128f. Dissertação (Mestrado) - Faculdade de Engenharia Agrícola, Universidade Estadual de Campinas, Campinas, SP, 2008.

SENSALE, G. Estudo comparativo entre as propriedades mecânicas dos concretos de alta resistência com cinza de casca de arroz. 2000. 288 f. Tese (Doutorado em Engenharia), Programa de Pós-Graduação em Engenharia Civil - PPGEC, Universidade Federal do Rio Grande do Sul, 2000.

SERSALE, R. et al. Chracterization and potencialuses of steel slag. Silicates Industriels, Bruxelles, v.51, p.163-170, 1986.

SHOUSUN, L. Effect of MgO in steel slag onsoundness of cement. In: INTERNATIONAL SYMPOSIUM ON THE CHEMISTRY OF CEMENT, 7, 1980. Proceedings... Paris, 1980. p.25-30. 
SILVEIRA, A. A. Contribuição ao estudo do efeito da incorporação de cinza de casca de arroz em concretos submetidos à reação álcali-agregado. Porto Alegre, 2007. Tese (Doutorado em Engenharia) - Programa de Pós-Graduação em Engenharia Civil - PPGEC, Universidade Federal do Rio Grande do Sul, 2007.

SILVEIRA, A. A. A Utilização de Adição de Cinza de Arroz com Vistas à Durabilidade de de Concretos: Estudo do Ataque por Sulfatos. 1996. Dissertação (Mestrado em Engenharia), Programa de Pós-Graduação em Engenharia Civil - PPGEC, Universidade Federal do Rio Grande do Sul, 1996.

SOUZA, P. S. L. Verificação da influência do uso de metacaulim de alta reatividade nas propriedades mecânicas do concreto de alta resistência. 2003. $287 \mathrm{f}$. Tese (Doutorado em Engenharia) - Universidade Federal do Rio Grande do Sul, 2003.

TIECHER, F. Reação álcali: agregado: avaliação do comportamento de agregados do sul do Brasil quando se altera o cimento utilizado. 2006.180 f. Dissertação (Mestrado em Engenharia) - Programa de Pós-Graduação em Engenharia Civil, Universidade Federal do Rio Grande do Sul, Porto Alegre, 2006.

VARGAS, A. S. Estudo da viabilidade do uso do pó de aciaria elétrica a arco na confecção de blocos de concreto para pavimentação. 2002. 148 f. Dissertação (Mestrado em Engenharia) - Programa Pós-Graduação em Engenharia de Minas, Metalúrgica e de Materiais, Universidade Federal do Rio Grande do Sul, Porto Alegre, 2002

VARGAS, A. S. Cinzas volantes álcali-ativadas para a obtenção de aglomerantes especiais. Tese (Doutorado), Programa de Pós-Graduação em Engenharia de Minas, Metalúrgica e de Materiais, Universidade Federal do Rio Grande do Sul,, 2006.

VIEIRA, F. M. P. Contribuição ao estudo da corrosão de armaduras em concretos com adição de sílica ativa. 2003. Tese (Doutorado em Engenharia), Programa de Pós-Graduação em Engenharia Civil - PPGEC, Universidade Federal do Rio Grande do Sul, 2003.

ZARDO, A. M.; BEZERRA, E. M.; MARTELLO, L. S.; SALVASTANO, H. Jr.; Utilização da cinza de bagaço cana-de-açúcar como "filler" em compostos com fibrocimento. I Conferência latino-americana de construção sustentável. X Encontro nacional de tecnologia do ambiente construído. 18-21, julho 2004. ISBN 85-89478-08-4. 